\title{
Papel da frutose 1,6-bisfosfato na osteoclastogênese e reabsorção óssea in
} vitro

Dissertação apresentada ao Programa de Pós-graduação em Farmacologia da Faculdade de Medicina de Ribeirão Preto da Universidade São Paulo como parte das exigências para obtenção do título de Mestre em Ciência.

Área de concentração: Farmacologia

Orientadora: Profa. Dra. Sandra Yasuyo Fukada

$$
\text { Ribeirão Preto, SP. }
$$

Faculdade de Medicina de Ribeirão Preto - Universidade de São Paulo 
Autorizo a reprodução e divulgação total ou parcial deste trabalho, por qualquer meio convencional ou eletrônico, para fins de estudo e pesquisa, desde que citada a fonte.

Catalogação na publicação

Serviço de Biblioteca e Documentação

Faculdade de Medicina de Ribeirão Preto da Universidade de São Paulo

Wilches Buitrago, Liseth Yamile

Papel da frutose 1,6-bisfosfato na osteoclastogênese e reabsorção óssea in vitro. Ribeirão Preto, 2017. 61 p.: il.; 30 cm.

Dissertação de mestrado, apresentada à Faculdade de Medicina de Ribeirão Preto-USP. Área de concentração: Farmacologia.

Orientadora: Fukada, Sandra Yasuyo.

1. Frutose 1,6-bifosfato. 2. Osteoclastos. 3. Reabsorção óssea. 4. Piruvato quinase M2. 


\section{FOLHA DE APROVAÇÃO}

Autora: Liseth Yamile Wilches Buitrago

Título: Papel da frutose 1,6-bisfosfato na osteoclastogênese e reabsorção óssea in vitro

Dissertação apresentada ao Programa de Pós-graduação em Farmacologia da Faculdade de Medicina de Ribeirão Preto da Universidade São Paulo como parte das exigências para obtenção do título de Mestre em Ciência.

Área de concentração: Farmacologia

Data da Defesa

\section{Banca examinadora}

$\operatorname{Prof}(\mathrm{a}) . \operatorname{Dr}(\mathrm{a})$.

Instituição: Assinatura:

Prof(a). Dr(a).

Instituição: Assinatura:

Prof(a). Dr(a).

Instituição: Assinatura:

Prof(a). Dr(a).

Instituição: Assinatura: 
Dedico este trabalho àqueles que são minha força:

À Virgem Maria.

Aos meus pais Teresa e Helbert,

Coquito e Rich, meus irmãos

Cesar, meu padrinho

Cuñis, meu cunhado.

¡Los adoro infinito! 


\section{AGRADECIMENTOS}

Gostaria de agradecer a todos que contribuíram para a execução deste trabalho.

Em especial agradeço:

À Profa. Dra. Sandra Fukada pela ajuda, orientação e todos os valiosos ensinamentos.

À minha família e amigos pelo apoio e companhia através da distância.

Às meninas do laboratório Thaise Taira, Alessandra Parreira, Mayara Gomes, Cecilia Costa, Thaís Xavier, Hine Takeda, Vilma Lima, Yumi Chokyu e Melinda Visalli pela ajuda na execução de experimentos e momentos de amizade.

Aos amigos Fabian Niño, Laura Melmar, Bryan Martinez, Federico Padilla e Andrés Aristizabal; e o resto do pessoal da Colômbia com quem pude compartilhar momentos de alegrias inesquecíveis.

Às pessoas brasileiras e de outras nacionalidades que tive o prazer de conhecer pelo recebimento e amabilidade.

Aos professores e pessoal do programa de Pós-graduação pelos ensinamentos e auxílios.

Ao Conselho Nacional de Desenvolvimento Científico e Tecnológico (CNPq) pela concessão da bolsa de estudos e à Fundação de Amparo à Pesquisa do Estado de São Paulo (FAPESP) pelo apoio financeiro para a realização deste trabalho. 


\section{RESUMO}

Wilches-Buitrago L. Papel da frutose 1,6-bisfosfato na osteoclastogênese e reabsorção óssea in vitro. Ribeirão Preto, 2017. 61 p. Dissertação (Mestrado) - Faculdade de Medicina de Ribeirão Preto, Universidade de São Paulo.

O remodelamento ósseo é um processo metabólico, dentro do qual os osteoblastos e os osteoclastos, participam ativamente. Portanto, qualquer alteração neste equilíbrio, pode provocar uma modificação na densidade mineral do osso, situação observada em certas doenças osteolíticas como osteoporose, artrite reumatóide e periodontite. Nos últimos anos, há um crescente interesse em avaliar o papel da glicólise na proliferação, sobrevivência e diferenciação dos diferentes tipos celulares. Em particular, tem sido evidenciado o efeito regulador da frutose 1,6-bisfosfato (FBP), um intermediário da via glicolítica de alta energia. Considerando que ainda não existem dados na literatura que correlacionem a FBP com o funcionamento dos osteoclastos, este trabalho tem por finalidade avaliar seu papel na osteoclastogênese e reabsorção óssea in vitro. Para isso, pré-osteoclastos murinos derivados da medula óssea foram diferenciados em osteoclastos na presença de M-CSF, RANKL e duas concentrações da FBP $(100$ e $300 \mu \mathrm{M})$. Os resultados obtidos amostram que a FBP inibe a diferenciação osteoclástica em uma relação dose-dependente, sem afetar a viabilidade celular. Observa-se também, que o tratamento com FBP diminui a expressão de genes marcadores como, Nfatc1, Trap e Catepsina $K(\mathrm{p}<0.01)$ e das proteínas NFATc1 e catepsina K. Como também, promove uma redução na atividade reabsortiva dos osteoclastos depois de $96 \mathrm{~h}$ de cultura. O efeito inibidor da FBP não depende da atividade da piruvato quinase M2 (PKM2). Em conjunto, estes dados sugerem que a FBP é um metabolito regulador importante da osteoclastogênese, demonstrando ser um agente potencial para o tratamento de doenças osteolíticas.

Palavras-chave: Frutose 1,6-bifosfato. Osteoclastos. Catepsina K. 


\section{ABSTRACT}

Wilches-Buitrago L. Role of the fructose 1,6-bisfosfato on osteoclastogenesis and bone resorption in vitro. Ribeirão Preto, 2017. 61 p. Master's degree - Faculdade de Medicina de Ribeirão Preto, Universidade de São Paulo.

Bone remodeling is a coordinated metabolic process, where the osteoblasts and osteoclasts participate actively. Therefore, any alteration in this balance may cause a change in the bone mineral density, a condition observed in certain bone loss-associated diseases such as osteoporosis, rheumatoid arthritis and periodontitis. Recently, there has been a growing interest in assessing the role of the glycolysis on the proliferation, survival, and differentiation of the different cell types. In particular, it has been demonstrated the protective effect of the Fructose 1,6-bisphosphate (FBP), a high-energy glycolytic intermediate. Considering that there is no evidence in the literature that associate FBP with the function of osteoclasts, this work aims to evaluate its role in osteoclastogenesis and bone resorption in vitro. To this end, murine bone marrow derived pre-osteoclasts were differentiated into osteoclasts in the presence of M-CSF, RANKL and two concentrations of FBP (100 and $300 \mu \mathrm{M})$. The results showed that FBP inhibits the differentiation of osteoclasts in a dose dependent manner, without affecting the cell viability. It was also observed that the treatment with the FBP decreases the expression of marker genes such as Nfatcl, Trap and Cathepsin $K(\mathrm{p}<0.01)$ and the NFATc1 and cathepsin K protein levels. As well, the treatment with FBP resulted in markedly fewer osteoclast activity after $96 \mathrm{~h}$ of culture. FBP osteoclast inhibitory effect does not involve Pyruvate Kinase M2 (PKM2) activity. Together, these data denote the important regulatory role of the FBP on osteoclastogenesis, proving to be a potential agent for the treatment of bone loss-associated diseases.

Key words: Fructose 1,6-bisphosphate. Osteoclasts. Cathepsin K. 


\section{LISTA DE ABREVIAÇÕES, SÍMBOLOS E SIGLAS}

ADP

ATP

BSA

cDNA

CTK

DMSO

DNA

MEM

$\alpha$-MEM

EDTA

ERK

FCFRP

FBP

GAPDH

JNK

MAPK

M-CSF

MTT

$\mathrm{ml}, \mu \mathrm{l}$

$\mu \mathrm{M}$

NFATc1

ng

OPG

PBS

PCR

$\mathrm{pH}$

PK

PKM2

PVDF
Adenosina difosfato

Adenosina trifosfato

Albumina de soro bovino

DNA complementar

Catepsina K

Dimetilsulfóxido

Ácido desoxirribonucléico (Deoxyribonucleic acid)

Minimum Essential Medium Eagle

Minimum Essential Medium Eagle Alpha Modifications

Ácido Tetracético Etilenodiamidina

Quinases Controladas pela Sinalização Extracelular (Extracellular Signal-Regulated Kinases)

Faculdade de Ciências Farmacêuticas de Ribeirão Preto

Frutose 1,6-bifosfato

Glyceraldehyde-3-Phosphate Dehydrogenase

c-Jun N-terminal Kinase

Proteíno-Quinases Ativadas por Mitógeno (Mitogen-Activated Protein Kinases)

Fator de estimulação de colónias de macrófagos

3-(4,5-Dimethylthiazol-2-yl)-2,5- Diphenyltetrazolium Bromide

mililitro, microlitro

micromolar

Fator nuclear de células $\mathrm{T}$ ativadas $\mathrm{c} 1$

nanograma

Osteoprotegerina

Tampão fosfato de sódio

Reação em cadeia polimerase

Potencial de hidrogênio iônico

Piruvato quinase

Piruvato quinase M2

Fluoreto Polivinidileno 
Proteíno-Quinases Ativadas por Mitógeno (Mitogen-Activated Protein Kinases)

$\operatorname{rcf}$

força centrífuga relativa (relative centrifugal force) ou força $\mathrm{g}: \mathrm{g}$

rpm rotações por minuto (revolutions per minute)

RANK

Receptor ativador do NF- $\kappa \mathrm{B}$

RANKL

Ligante do receptor ativador do NF- $\kappa \mathrm{B}$

RNA

Ácido ribonucléico (Ribonucleic acid)

RNAm

Ácido ribonucléico mensageiro

SDS

Dodecil sulfato de sódio

SFB

Soro Fetal Bovino

TBS-T

Tris-buffered saline com Tween 20

TRAP

Fosfatase resistente ao tartarato

$\mathrm{v} / \mathrm{mA}$

voltagem e miliampére

x $g$

força $\mathrm{g}$ (units of gravity) 


\section{ÍNDICE DE FIGURAS}

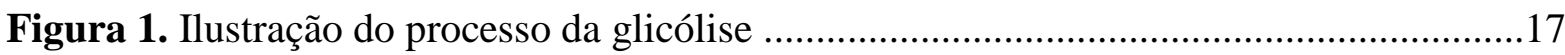

Figura 2. Ilustração da estrutura molecular da frutose 1,6-bisfosfato (FBP) ........................18

Figura 3. Efeito da frutose 1,6-bifosfato (FBP) sobre a osteoclastogênese in vitro ................33

Figura 4. Número de osteoclastos formados após 96 h de diferenciação e estimulação com frutose 1,6-bifosfato (FBP)

Figura 5. Área dos osteoclastos formados após 96 h de diferenciação e estimulação com frutose 1,6-bifosfato (FBP)

Figura 6. Efeito da frutose 1,6-bifosfato (FBP) sobre a atividade de TRAP no lisado celular de osteoclastos .35

Figura 7. Efeito da frutose 1,6-bifosfato (FBP) sobre a viabilidade celular 36

Figura 8. Efeito da frutose 1,6-bifosfato (FBP) sobre a expressão relativa de RNAm de Nfatcl 37

Figura 9. Efeito da frutose 1,6-bifosfato (FBP) sobre a expressão relativa de RNAm de Trap 37

Figura 10. Efeito da frutose 1,6-bifosfato (FBP) sobre a expressão relativa de RNAm de Catepsina $\mathrm{K}$ .38

Figura 11. Efeito da frutose 1,6-bifosfato (FBP) sobre a expressão da proteína NFATc1 nos osteoclastos

Figura 12. Efeito da frutose 1,6-bifosfato (FBP) sobre a expressão da proteína catepsina $K$ (CTK) nos osteoclastos

Figura 13. Áreas de reabsorção óssea formadas pelos osteoclastos diferenciados com M-CSF e RANKL na presença da frutose 1,6-bifosfato (FBP)

Figura 14. Quantificação das área de reabsorção/poço formadas pelos osteoclastos diferenciados com M-CSF e RANKL na presença da frutose 1,6-bifosfato (FBP) 41

Figura 15. Número de osteoclastos formados após 96 h de diferenciação e estimulação com frutose 1,6-bifosfato (FBP), a partir de camundongos Lysm ${ }^{\mathrm{Cre} /-} \mathrm{PKM} 2^{\mathrm{f} / \mathrm{f}}$ e dos $\mathrm{Lysm}^{\mathrm{Cre} /}$ 42

Figura 16. Área de osteoclastos formados após 96 h de diferenciação e estimulação com frutose 1,6-bifosfato (FBP), a partir de camundongos $\mathrm{Lysm}^{\mathrm{Cre} /-} \mathrm{PKM}^{\mathrm{f} / \mathrm{f}}$ e dos Lysm ${ }^{\mathrm{Cre} /}$ 


\section{SUMÁRIO}

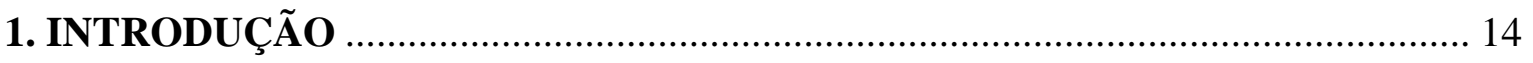

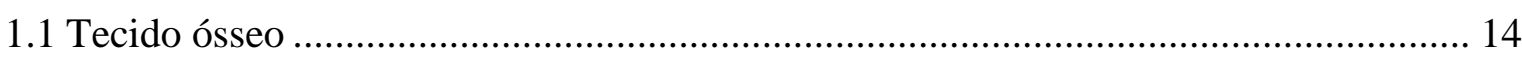

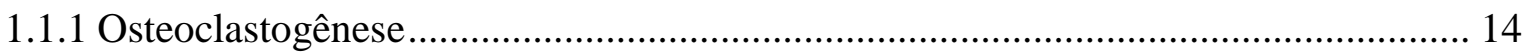

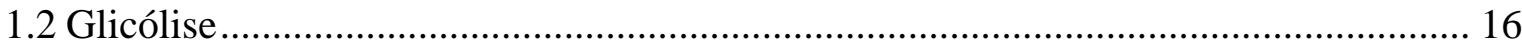

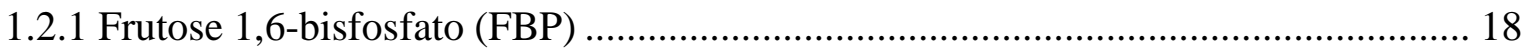

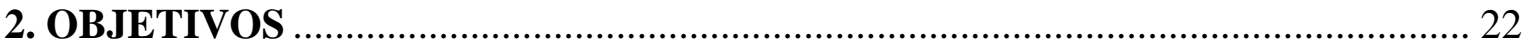

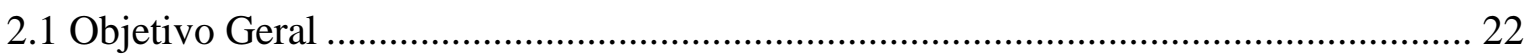

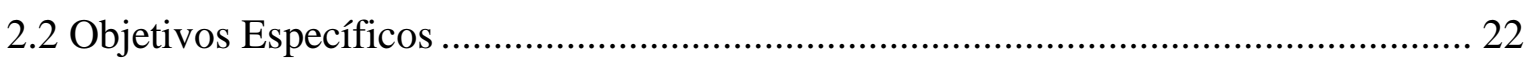

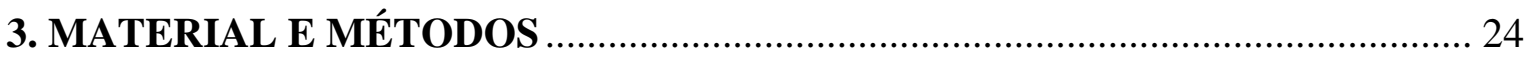

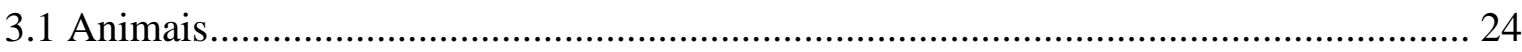

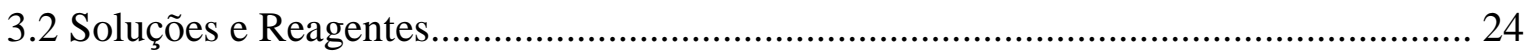

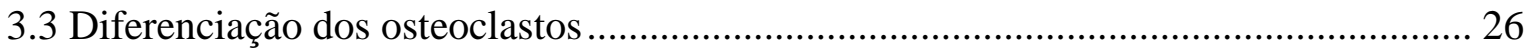

3.4 Parâmetros de avaliações da diferenciação e ativação dos osteoclastos ...................... 27

3.4.1 Determinação do número de osteoclastos pelo ensaio histoquímico de TRAP ........ 27

3.4.2 Determinação da atividade de TRAP por espectrofotometria ................................... 28

3.4.3 Quantificação da viabilidade celular por espectrofotometria - MTT........................ 28

3.4.4 Expressão dos genes marcadores de osteoclastos como Nfatc1, Trap e Catepsina K por

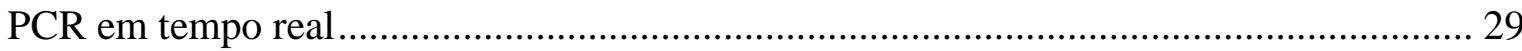

3.4.5 Expressão das proteínas NFATc1 e catepsina K por Western Blot ........................... 29

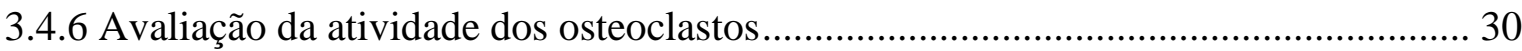

3.5 Determinação do mecanismo de ação da FBP na osteoclastogênese: participação da

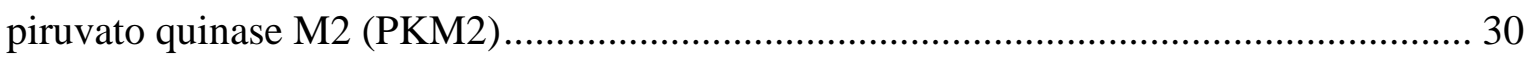

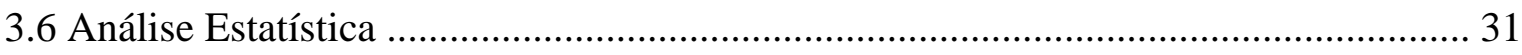

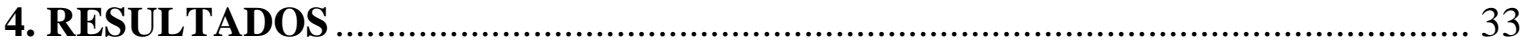

4.1. Estudar se a estimulação com diferentes concentrações da frutose 1,6-bisfosfato (FBP), interfere na osteoclastogênese e atividade dos osteoclastos in vitro................................. 33

4.1.1 Efeito da FBP sobre a osteoclastogênese in vitro ...................................................... 33

4.1.2 Efeito da FBP sobre a atividade de TRAP no lisado celular de osteoclastos ............ 35

4.1.3 Efeito da FBP sobre a viabilidade celular ............................................................. 35

4.1.4 Efeito da FBP sobre a expressão relativa de RNAm de Nfatc1, Trap e Catepsina $K$ nos

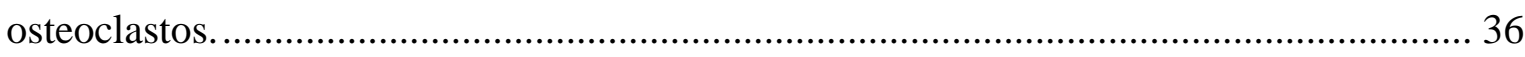


4.1.5 Efeito da FBP sobre os níveis de proteína de NFATc1 e catepsina K nos osteoclastos 38

4.1.6 Efeito da FBP sobre a atividade ósteo-reabsortiva dos osteoclastos .... 40

4.2 Determinar o mecanismo de ação da FBP na osteoclastogênese: participação da piruvato

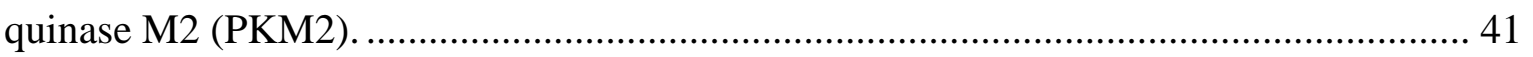

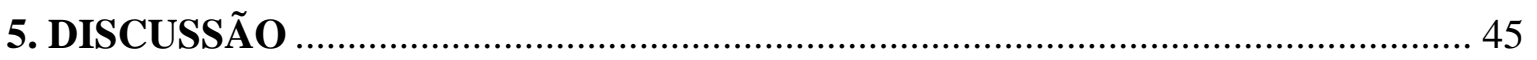

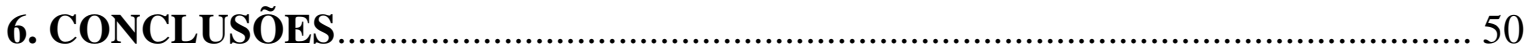

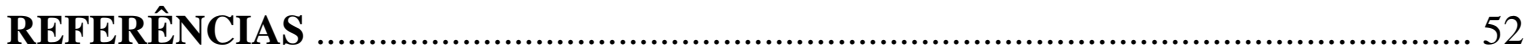

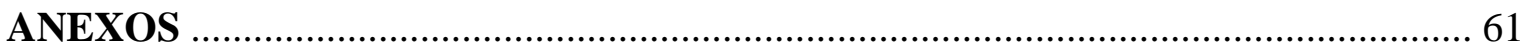


INTRODUÇÃO 


\section{INTRODUÇÃO}

\subsection{Tecido ósseo}

O osso é um tecido rígido especializado, constituído essencialmente por dois componentes estruturais: matriz orgânica e matriz inorgânica, que lhe permitem desempenhar múltiplas funções mecânicas e metabólicas. Na composição orgânica encontra-se $2 \%$ de células e $98 \%$ de matriz extracelular. Na matriz extracelular, o colágeno tipo I é o principal elemento perfazendo $95 \%$ e os $5 \%$ restantes são representados por polissacarídeos, lipídeos e fosfolipídeos. Entre os componentes inorgânicos encontra-se o cálcio e o fósforo, que formam a hidroxiapatita $\left(\mathrm{Ca}_{10}\left(\mathrm{PO}_{4}\right)_{6}(\mathrm{OH})_{2}\right)$ e outros elementos como magnésio, sódio, potássio e, em menor concentração, zinco, manganês, flúor e molibidênio (Buckwalter et al., 1996; Kaplan, 1991).

Os principais fenótipos celulares associados ao osso são os osteócitos, os osteoblastos e os osteoclastos. Os osteoblastos são células de origem mesenquimal, responsáveis pela síntese de componentes orgânicos da matriz óssea. Os osteócitos ficam dentro da matriz extracelular, após ter sido envolto pela matriz depositada por osteoblastos. Em contrapartida, os osteoclastos são células de origem hematopoiética da linhagem mielóide responsáveis pela reabsorção da matriz óssea (Alford et al, 2015).

O tecido ósseo sofre um constante processo de homeostase/remodelação, dentro do qual os osteoblastos e os osteoclastos são os principais protagonistas; e esse processo é regulado ainda por uma série de elementos e fatores sinalizadores. Portanto, qualquer alteração neste equilíbrio, pode provocar uma modificação na densidade mineral óssea, situação observada em certas doenças inflamatórias como osteoporose, artrite reumatóide e periodontite (Adamopoulos \& Mellins, 2015; Penoni et al., 2016).

\subsubsection{Osteoclastogênese}

A osteoclastogênese ou formação dos osteoclastos ocorre em três estágios. No estágio inicial, os precursores de monócitos e/ou macrófagos que são as células precursoras desenvolvem-se em pré-osteoclastos; em seguida, os pré-osteoclastos mononucleares fundem para se tornar em osteoclastos multinucleados não-funcionais, e finalmente, aqueles osteoclastos multinucleados não-funcionais são ativados em células maduras capazes de reabsorver osso 
(Tompkins, 2016). Este processo de diferenciação é regulado por diversos fatores, principalmente por: i) o fator estimulador de colônias de macrófagos (M-CSF), e ii) o ligante do receptor ativador do NF- $\kappa \mathrm{B}$ (RANKL).

O M-CSF, também conhecido como CSF-1, atua no receptor C-Fms (CSF1R/MCSFR) expresso em monócitos e macrófagos (Hattersley et al., 1991). Esta citocina fornece os sinais essenciais para a sobrevivência e a proliferação celular, e adicionalmente, regula a expressão do receptor RANK. Em sequência, o RANKL é uma citocina que pertence a superfamília do TNF e quando ligado, ativa o receptor RANK, o qual é expresso em monócitos, macrófagos e em pré-osteoclastos (Kong et al., 1999). A ligação RANKL-RANK promove o recrutamento da molécula adaptadora TRAF-6 (fator 6 associado ao receptor de TNF), a qual leva a

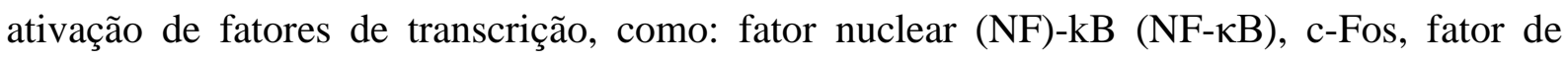
transcrição associado a microftalmia (MITF), fator nuclear de células $\mathrm{T}$ ativadas c1 (NFATc1), as quais são importantes para os diferentes estágios de diferenciação dos osteoclastos (Boyce et al., 2005; Yu et al., 2011). Em particular, o NFATc1 é considerado o principal regulador da diferenciação dos osteoclastos visto que células embrionárias deficientes de NFATc1, em resposta à estimulação com RANKL, não diferenciam em osteoclastos (Takayanagi et al., 2002). Foi demostrado que este fator de transcrição apresenta um papel essencial na osteoclastogênese, regulando a expressão de inúmeros genes relacionados à diferenciação e fusão celular como calcitonin receptor (CTR), osteoclastassociated receptor (OSCAR), dendritic cell-specific transmembrane protein (DC-STAMP) e $\mathrm{d} 2$ isoform of vacuolar ATPase $\mathrm{V}_{0}$ domain (Atp6v0d2), e de genes relacionados à ativação dos osteoclastos como fosfatase resistente ao tartarato (TRAP) e catepsina K (Kim \& Kim, 2014). Os resultados obtidos, demostram que NFATc1 liga-se diretamente às regiões promotoras das moléculas mediadoras de fusão Atp6v0d2 e DC-STAMP, e induz a expressão desses genes, regulando assim a maturação dos osteoclastos (Kim et al., 2008).

Do mesmo modo, existe ativação de MAP Kinases (p.ex.: Extracellular SignalRegulated Kinases (ERK), c-Jun N-terminal Kinase (JNK) e p38), induzida pelo sinal de RANKL, que finalmente leva à expressão dos fatores de transcrição mencionados anteriormente c-Fos, MITF e NFATc1 (Lee et al., 2016). Tem sido mostrado que a estimulação de precursores de osteoclastos com RANKL ativa a via de sinalização intracelular MAPK p38 (Lin et al., 2015). Assim, o ERK1 é um regulador positivo da formação e atividade dos osteoclastos (He et al., 2011). Neste contexto, a via das MAPK (Mitogen Activated Protein Kinases - Proteíno-Quinases Ativadas por Mitógeno) é um sistema de sinalização intracelular que envolve uma cascata de proteinas-quinase específicas 
de serina/treonina que respondem a estímulos extracelulares (mitógenos) e regulam várias atividades celulares tais como expressão gênica, mitose, diferenciação, proliferação, sobrevivência celular e apoptose. Os sinais são transmitidos por meio de fosforilação sequencial e ativação desses proteínas. As quatro principais MAPK que participam do mecanismo de sinalização, incluem a via ERK1/2, ERK5, p38 e JNK. A via MAPK/ERK5 é ativada em resposta aos estímulos para a proliferação, diferenciação e sobrevivência das células (Nithianandarajah-Jones et al., 2012; Nishimoto \& Nishida, 2006). A ativação de MAPK/ERK5 é importante para a osteoclastogênese (Amano et al., 2015).

No terceiro estágio, para que osteoclastos maduros possam reabsorver o osso, eles necessitam executar um remodelamento citoesquelético, polarização da membrana plasmática, redistribuição de transportadores e organelas, e um intenso tráfego endossomal. A reabsorção óssea inicia com a formação da zona de selamento que é caracterizada pela adesão celular na superfície óssea mineralizada, por meio de Integrina tipo alfa v beta 3 (Integrina $\left.\alpha_{v} \beta 3\right)$ e formação de lacunas de reabsorção, para onde são secretados ácido e enzimas proteolíticas. A manutenção do $\mathrm{pH}$ ácido, por $\mathrm{H}^{+} \mathrm{ATPase}$ vacuolares, nestas lacunas são importantes para amplificação da atividade das enzimas proteolíticas secretadas de vesículas, como o TRAP, catepsina K e matriz metaloproteinase-9 (MMP-9), permitindo assim a desmineralização e degradação de colágeno (Cappariello et al., 2014).

A formação e ativação de osteoclastos é um processo complexo que exige um alto gasto de energia. Considera-se que os osteoclastos sofrem uma adaptação metabólica para satisfazer o aumento da demanda de trifosfato de adenosina (ATP) para a diferenciação (incluindo proliferação, migração e fusão para formar células gigantes multinucleadas) e maturação, bem como para a biossíntese e atividade dos constituintes celulares envolvidos no processo de reabsorção óssea (Kim et al., 2007; Lee et al., 2010). Diante disso, foi observado que intermediários das vias metabólicas podem regular as demandas de ATP necessárias para a diferenciação de osteoclastos (Fong et al., 2013; Williams et al., 1997).

\subsection{Glicólise}

O metabolismo da glicose ou glicólise, o qual é induzido pela insulina, apresenta um papel crucial, porque regula a necessidade energética (produção de ATP: adenosina trifosfato) para o funcionamento celular, como também para alguns processos fisiológicos e vias de sinalização. A glicólise ocorre no citoplasma celular e é uma sequência de reações 
bioquímicas catalisadas por enzimas, na qual a glicose é oxidada produzindo moléculas de piruvato/ácido pirúvico e ATP (Figura 1). O ácido pirúvico formado nesta via, com a presença de oxigênio, é usado na mitocôndria no ciclo de Krebs (ácido cítrico ou Ciclo dos Ácidos Tricarboxílicos, em inglês TCA). No entanto, quando não há oxigênio suficiente, o piruvato é transformado em ácido lático ou etanol (fermentação).

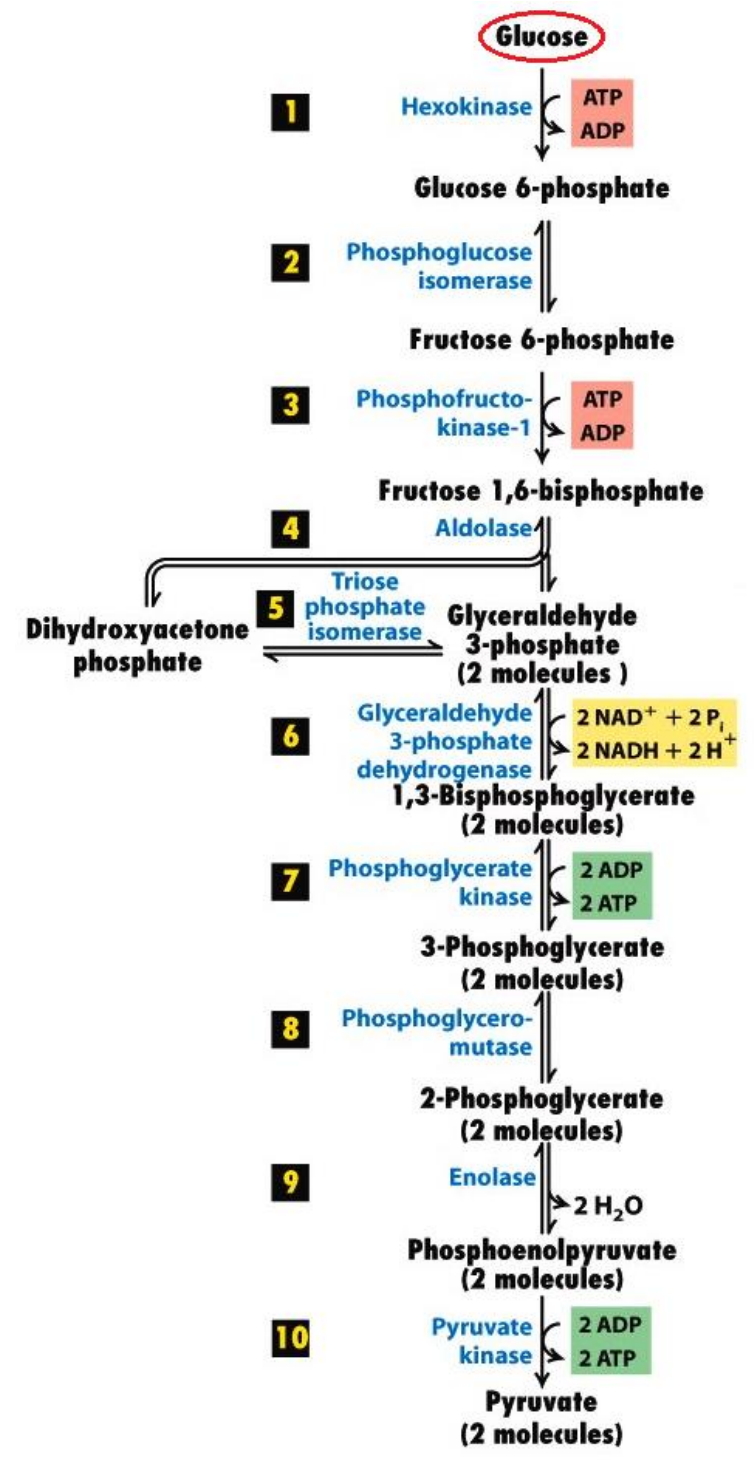

Figura 1. Ilustração do processo da glicólise. Nesta sequência metabólica a glicose é oxidada produzindo moléculas de piruvato/ácido pirúvico e ATP (Molecular Cell Biology, W. H. Freeman and Company, 6th edition, 2008).

Poucos estudos, publicados até o momento, dão enfoque ao papel regulador da glicólise na diferenciação, proliferação e sobrevivência dos diferentes tipos celulares envolvidos na remodelação óssea, incluindo os osteoclastos (Ferron et al., 2010; Mueller et al., 2013). Por exemplo, foi visto que a insulina induz a proliferação e diferenciação de osteoblastos humanos (linhagem MG-63), através das vias de sinalização MAPK (MAP 
Kinases) e PI3K (phosphatidylinositol 3-kinase) (Yang et al., 2010). Da mesma maneira, um trabalho utilizando microarrays demonstrou que a insulina pode ter um papel regulador similar ao RANKL em precursores de osteoclastos (Kim \& Lee, 2014).

Observa-se também em macrófagos murinos obtidos da medula óssea, que a presença de glicose e glutamina, são essenciais para a osteoclastogênese e reabsorção óssea (Indo et al., 2013). A avaliação in vitro e in vivo mostra que uma pequena fração de piruvato estimula a osteoclastogênese, associada com um aumento nos níveis de AMPK (AMP-activated protein kinase) (Fong et al., 2013).

\subsubsection{Frutose 1,6-bisfosfato (FBP)}

A frutose 1,6-bisfosfato é um metabólito intermediário da via glicolítica altamente energético, produzido por fosforilação da frutose-6-fosfato pela enzima fosfofructoquinase-1 (Figura 1, etapa 3). A sua estrutura molécular é composta por um monossacarídeo frutose fosforilado nos carbonos, C-1 e C-6 (Figura 2). Em condições fisiológicas, a grande maioria da glicose presente na célula é convertida a FBP.

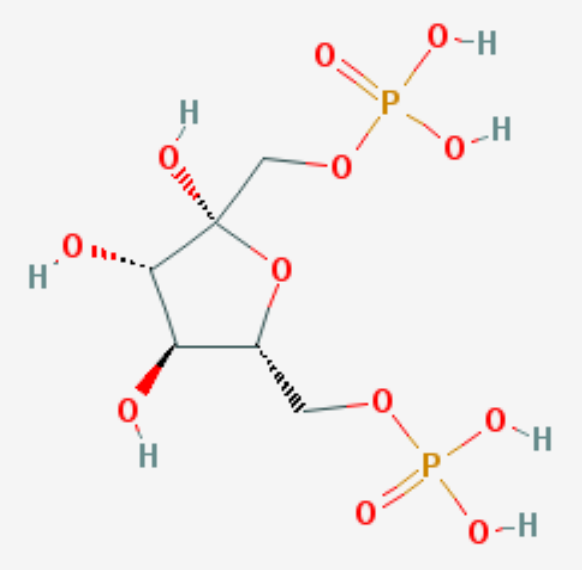

Figura 2. Ilustração da estrutura molecular da frutose 1,6-bisfosfato (FBP). Trata-se de uma molécula polar composta por um monossacarídeo frutose fosforilado nos carbonos, $\quad$ C-1 e C-6. (PubChem Compound Database. pubchem.ncbi.nlm.nih.gov/compound/10267\#section=Top).

Diversos estudos da atividade da FBP tem demonstrando que este composto é um agente regulador/protetor em diferentes mecanismos teciduais e celulares, como os neurológicos, imunológicos e cardiovasculares (Alva et al., 2106; Cohen et al., 2006; Lopes et al., 2006; Planas et al., 1993). Foi mostrado que o tratamento com FBP promoveu uma redução do infiltrado neutrofílico, da hipernocicepção e do edema articular induzido por 
zimosan (AIZ). Além disso, promoveu a redução das citocinas proinflamatórias, como IL-1ß, TNF- $\alpha$ e IL-6, bem como o aumento da citocina anti-inflamatória IL-10, no sítio inflamatório (Veras \& Alves Filho, 2014). Outrossim, um estudo evidenciou o efeito protetor da FBP na função renal em modelo experimental de nefrotoxicidade induzida pela cisplatina (Azambuja et al., 2011). Outro trabalho mostra que a FBP reduz a mortalidade da sepse induzida pela Candida albicans e previne a diminuição de plaquetas (Santos et al., 2012). Ademais, animais tratados com FBP apresentam um aumento na sobrevida em infecções por Escherichia coli (Nunes et al., 2003).

Porém, ainda não foi identificado claramente o mecanismo pelo qual a FBP pode induzir o efeito protetor. Estudos recentes demonstram que FBP é capaz de entrar na célula, e o pouco dessa entrada no meio intracelular é suficiente para induzir a proteção e fazer com que aumente o fluxo glicolítico e a produção de ATP (Lian \& Xu, 2008; Lin et al., 2012; Xu \& Stringer, 2008). Um mecanismo protetor proposto foi a ativação de vias de sinalização envolvidas na proliferação, diferenciação e sobrevivência celular como MAPK/ERK, JNK e p38 (Fahlman et al., 2002; Park et al., 2004). Similarmente, a FBP é ainda capaz de ativar vias que modulam respostas imunológicas e inflamatórias (Alves Filho et al., 2004; Seok et al., 2015).

No processo da glicólise, a FBP se encontra antes à reação da enzima piruvato quinase (PK), sobre o qual FBP atua como um ativador alostérico. Esta enzima participa na última etapa, catalisando a transformação do fosfoenolpiruvato (PEP) e ADP em piruvato e ATP (Figura 1). A PK em mamíferos consiste em quatro isoformas: a L (PKL) e R (PKR) que são codificadas pelo gene PKLR (1q22), e as isoformas M1 (PKM1) e M2 (PKM2) codificadas pelo gene PKM2 (15q23) por splicing alternativo. Cada uma exibe propriedades cinéticas específicas, em consideração com as necessidades metabólicas do tecido no qual expressamse. Assim, a isoforma PKR está presente nas hemácias, enquanto a isoforma PKL está no fígado e no rim. PKM1 é predominante expresso no músculo esquelético, coração e cérebro, e PKM2 está presente na maioria das células, principalmente em células proliferativas e cancerosas (Wong et al., 2013).

A atividade da PK está determinada pela sua configuração enzimática, em tetrâmero, dímero ou monômero. PKL, PKR, e PKM1 formam tetrâmeros, enquanto, PKM2 existe como dímero e tetrâmero. O dímero da PKM2 é menos ativo na conversão de PEP para piruvato e ATP, do que o tetrâmero. A PKM2 precisa da ligação a um ativador para provocar a atividade enzimática. Como dito anteriormente, a sua ativação alostérica pode ser feita endogenamente pela frutose-1,6-bifosfato (FBP), idem, pelo serine e succinyl aminoimidazole carboxamide 
ribose-50-phosphate (SAICAR) (Chaneton et al., 2012; Jurica et al.,1998; Keller et al., 2012). Também pode ser ativada pelo DASA-58 e TEPP-46 (Anastasiou et al., 2012; PalssonMcDermott et al., 2015).

$\mathrm{Na}$ ausência de ativador, a PKM2 assume a forma de monômero ou dímero, a qual pela falta de atividade enzimática permite aos metabólitos intermediários, ser utilizados para a síntese de nucleotídeos, aminoácidos e lipídios, e a produção de NADPH. A PKM2 dimérica pode transladar para o núcleo onde promove a ativação do fator de transcrição HIF-1 $\alpha$, e a expressão dos genes LDHA e GLUT-1, assim como da citocina IL-1 $\beta$. Aliás, PKM2 pode interagir com outros fatores de transcrição, tais como a STAT3, histona H3 e JMJD5 (AlvesFilho \& Pålsson-McDermott, 2016), regulando assim genes importantes para a proliferação e a glicólise. Por essa razão, pesquisadores têm tido interesse em avaliar seu envolvimento no câncer e inflamação (Israelsen \& Vander Heiden, 2015; Luo \& Semenza, 2012).

Considerando a importância da via glicolítica na osteoclastogênese e que ainda não existem dados na literatura que correlacionem frutose-1,6-bisfosfato (FBP) com o funcionamento dos osteoclastos. Além do que dados preliminares do nosso laboratório evidenciaram que ocorre dimerização de piruvato quinase M2 (PKM2) durante a diferenciação dos osteoclastos. A hipótese do presente trabalho foi que a FBP teria um papel regulador na osteoclastogênese e perda óssea dependente da PKM2. 
OBJETIVOS 


\section{OBJETIVOS}

\subsection{Objetivo Geral:}

Avaliar o papel da frutose 1,6-bisfosfato (FBP) na osteoclastogênese e reabsorção óssea in vitro.

\subsection{Objetivos Específicos:}

2.2.1. Estudar se a estimulação com diferentes concentrações de frutose 1,6-bisfosfato (FBP), interfere na osteoclastogênese e atividade dos osteoclastos in vitro.

2.2.2. Determinar o mecanismo de ação da FBP na osteoclastogênese: participação da piruvato quinase M2 (PKM2). 
MATERIAL E MÉTODOS 


\section{MATERIAL E MÉTODOS}

\subsection{Animais}

No presente estudo, foram utilizados camundongos C57/BL6, Lysm ${ }^{\mathrm{Cre} /}$ (controle) e $\mathrm{Lysm}^{\mathrm{Cre} /-} \mathrm{PKM}^{\mathrm{f} / \mathrm{f}}$ (gerados para deficiência específica do gene da PKM2 em macrófagos) machos, de 5-7 semanas de idade, obtidos do Biotério Central do Campus da USP-RP. Os protocolos experimentais foram submetidos à aprovação prévia pelo Comitê de Ética do Uso de Animais da FCFRP-USP (Processo ${ }^{\circ}$. 15.1.750.60.0, ver ANEXO)

\subsection{Soluções e Reagentes}

\section{Solução de Ketamina e Xilazina:}

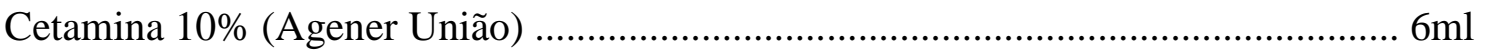

Xilazina 2\% (Sytnec) ......................................................................... 3,6ml

Salina 0.9 \% q.s.p ................................................................................. 50,4ml

A solução estocada a $4{ }^{\circ} \mathrm{C}$.

\section{Tampão de lise:}

Cloreto de amônio $\left(\mathrm{NH}_{4} \mathrm{Cl}\right.$, Synth) ................................................................. 4,02g

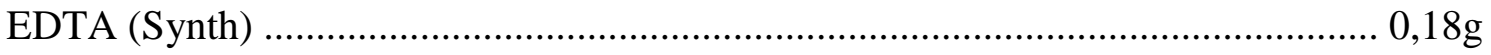

Bicarbonato de sódio $\left(\mathrm{NaHCO}_{3}\right.$, Synth) ...................................................... 0,42g

Água de Milli-Q q.s.p. .............................................................................. $500 \mathrm{ml}$

$\mathrm{O}$ pH ajustado para $\mathrm{pH} 7,2-7,4$; filtrada e estocada a $4{ }^{\circ} \mathrm{C}$.

\section{Meio $\alpha$-MEM incompleto:}

Minium Essential Medium Alpha Medium (Gibco®) - 1 sachê ............................ 10,2g

Bicarbonato de sódio $\left(\mathrm{NaHCO}_{3}\right.$, Synth) …........................................................... 2,2g

Água de Milli-Q q.s.p. .......................................................................... 1000

$\mathrm{O} \mathrm{pH}$ ajustado para $\mathrm{pH} 6,8$; filtrada e estocada a $4{ }^{\circ} \mathrm{C}$. 


\section{Meio $\alpha$-MEM completo/suplementado:}

Soro Bovino Fetal inativado (Gibco®) …........................................... 10 10ml

Estreptomicina $(10 \mathrm{mg} / \mathrm{ml}) /$ Penicilina (10 unidades) (antibiótico, Gibco®) .............. 1ml

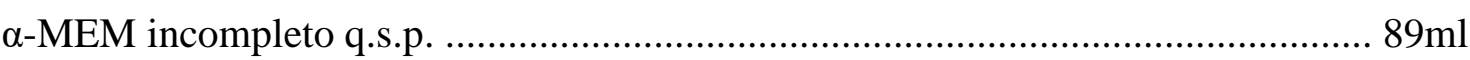

A solução filtrada e estocada a $4{ }^{\circ} \mathrm{C}$.

\section{Solução de Tampão Salina-fosfato (PBS) 10X (Solução estoque):}

Cloreto de Sódio (NaCl, Synth) ……………...................................................... 80 g

Cloreto de Potássio (KCl, Synth) ….............................................................. $2 \mathrm{~g}$

Fosfato de Sódio dibásico anidro $\left(\mathrm{Na}_{2} \mathrm{HPO}_{4}\right.$, Synth) ...................................... 11,45g

Fosfato de Potássio monobásico anidro $\left(\mathrm{KH}_{2} \mathrm{PO}_{4}\right.$, Synth) ................................... $2 \mathrm{~g}$

Água deionizada Milli-Q q.s.p. ................................................................. 1000ml

$\mathrm{O} \mathrm{pH}$ ajustado para 6,8 e estocada a $4{ }^{\circ} \mathrm{C}$.

\section{PBS:}

PBS10X $100 \mathrm{ml}$

Água Milli-Q q.s.p $900 \mathrm{ml}$

A solução filtrada e estocada a $4{ }^{\circ} \mathrm{C}$.

\section{Tampão de Corrida 10X (Solução estoque):}

Tris base (Trizma base; Sigma-Aldrich) …................................................. 15,15g

Glicina (Sigma-Aldrich) ........................................................................ 72, $05 \mathrm{~g}$

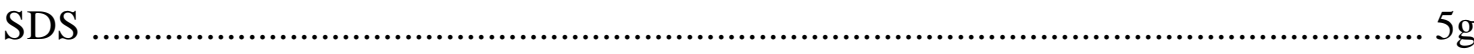

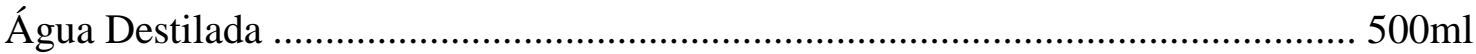

\section{Tampão de Corrida:}

Solução de Tampão de Corrida 10X ................................................................ 50ml

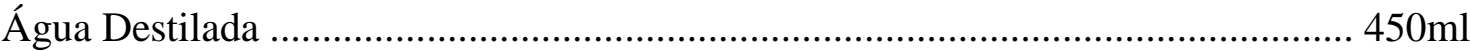

\section{Tampão de Transferência Úmida}

Tris base (Trizma base; Sigma-Aldrich) ........................................................ 3,6g

Glicina (Sigma-Aldrich) .................................................................... 17,28g

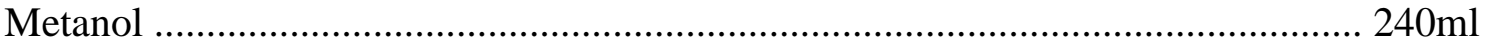

Água Destilada .................................................................. Avolumar para 1200ml 


\section{Solução de TBST-T 10X (Solução estoque):}

Tris-HCl $10 \mathrm{mM}$ $7,86 \mathrm{~g}$

$\mathrm{NaCl} 150 \mathrm{mM}$ $43,8 \mathrm{~g}$

Tween $200,1 \%$ $2500 \mu 1$

Água Milli-Q q.s.p $500 \mathrm{ml}$

$\mathrm{O}$ pH ajustado para $\mathrm{pH} 7,2-7,4$; e estocada a $4{ }^{\circ} \mathrm{C}$.

\section{Solução de TBST-T:}

Solução de TBST-T 10X $50 \mathrm{ml}$ Água Milli-Q q.s.p $450 \mathrm{ml}$

\subsection{Diferenciação dos osteoclastos}

A diferenciação de osteoclastos murinos foi realizada a partir de cultura primária com células obtidas da medula óssea. Para isso, os camundongos foram eutanasiados após receberam anestesia com injeção intramuscular da solução Ketamina-Xilazina, na proporção de $0,1 \mathrm{ml} / 1 \mathrm{Kg}$ de peso corporal seguido de deslocamento cervical. Em seguida, o fêmur e tíbia foram assepticamente removidos, o tecido mole removido com lâmina de bisturi e colocados em meio de cultura $\alpha$-MEM incompleto. $\mathrm{Na}$ cabine de fluxo laminar os ossos foram mergulhados em álcool e meio $\alpha$-MEM completo e as epífises foram cortadas para exposição do canal medular. Cada osso foi depositado pela extremidade cortada em tubo de $0,6 \mathrm{ml}$ furado, o qual estava colocado dentro de um tubo de $1,5 \mathrm{ml}$ que foram centrifugados a 10.000 rpm por 30 segundos a $4{ }^{\circ} \mathrm{C}$, o conteúdo medular foi ressuspendido em tampão de lise e novamente centrifugadas a $360 \mathrm{x} g(\mathrm{rcf})$ por 5 minutos a $4^{\circ} \mathrm{C}$. O sobrenadante foi retirado cuidadosamente e o pelet ressuspendido em $5 \mathrm{ml}$ de meio $\alpha$-MEM completo. As células foram novamente centrifugadas, o sobrenadante desprezado e então ressuspendidas em $8 \mathrm{ml}$ de meio $\alpha$-MEM completo e passadas pela redinha de $100 \mu \mathrm{m}$ Nylon (Cell Strainer, BD Falcon, USA) para remoção de debris celular. Em seguida foi feita a contagem de células em câmara de Neubauer utilizando o corante azul de tripan 0,4\%. A suspensão de células obtidas foi cultivada em placa de Petri (Corning, NY, USA) (contendo $13 \times 10^{6}$ células/placa) com M-CSF (30ng/ml, R\&D System) em meio de cultura $\alpha$-MEM suplementado, por 3 dias (Prates et al., 2014). 
Após 3 dias de cultura, as células aderentes, as quais denominamos de préosteoclastos, foram lavadas e destacadas com $5 \mathrm{ml}$ de PBS gelado e com o auxílio de um scraper de plástico (Cell Scraper; Corning). A solução contendo os macrófagos foi centrifugada a 360 x $g$ por 5 minutos a $4^{\circ} \mathrm{C}$ e ressuspendidas em $8 \mathrm{ml}$ de meio $\alpha$-MEM completo. A suspensão de células obtidas foi cultivada em placas (24 ou 96 poços, de acordo com o protocolo proposto) na presença de M-CSF (30ng/ml) e RANKL (10ng/ml, R\&D System) em meio de cultura $\alpha$-MEM completo, por até 4 dias.

As culturas foram realizadas na presença de duas concentrações de D-Fructose 1,6bisphosphate (100 e $300 \mu \mathrm{M}$, Sigma-Aldrich). Dessa maneira, os grupos experimentais foram: 0 (pré-osteoclastos diferenciados com M-CSF e RANKL); 100 (pré-osteoclastos diferenciados com M-CSF e RANKL na presença da FBP $100 \mu \mathrm{M}$ ) e 300 (pré-osteoclastos diferenciados com M-CSF e RANKL na presença da FBP $300 \mu \mathrm{M}$ ).

\subsection{Parâmetros de avaliações da diferenciação e ativação dos osteoclastos}

Para cumprir o primeiro objetivo específico foram utilizadas as culturas de células provenientes dos camundongos C57/BL6. As características dos osteoclastos foram avaliadas nos dias 3 ou 4 de diferenciação nos diferentes grupos, utilizando as seguintes metodologias:

a) ensaio histoquímico de coloração de células multinucleadas sensíveis ao TRAP;

b) ensaio espectrofotométrico para determinar a atividade de TRAP;

c) ensaio espectrofotométrico de viabilidade celular MTT;

d) expressão dos genes marcadores de osteoclastos como Nfatc1, Trap e Catepsina K por PCR em tempo real;

e) expressão das proteínas NFATc1 e catepsina K por Western Blot, utilizando anticorpos específicos; e

f) cultura de osteoclastos em placas de osso (Corning ${ }^{\mathrm{TM}}$ Osteo Assay Surface) para determinar a capacidade de reabsorção destas células.

\subsubsection{Determinação do número de osteoclastos pelo ensaio histoquímico de TRAP}

A detecção de osteoclastos foi realizada pela reação de fosfatases ácidas resistentes ao tartarato - TRAP (Kit Sigma 387-A; Sigma-Aldrich). Os pré-osteoclastos cultivados em placa Costar (Corning) de 96 poços (contendo $2 \times 10^{4}$ células/poço) foram diferenciados e 
estimulados com FBP por $96 \mathrm{~h}$. Após esse período, o meio foi removido e as células foram lavadas 2x com PBS, fixadas e incubadas por 60 minutos a $37^{\circ} \mathrm{C}$ na solução corante contendo tartaratos, ao abrigo da luz, de acordo com as instruções do fabricante. Em seguida, os osteoclastos foram fotografados ao microscópio óptico. As células multinucleadas TRAP ${ }^{+}$ (com três ou mais núcleos) foram analisadas utilizando o software de análise de imagem ImageJ.

\subsubsection{Determinação da atividade de TRAP por espectrofotometria}

A atividade de TRAP (uma característica da formação de osteoclastos) foi determinada pelo ensaio espectrofotométrico de fosfatases ácidas resistentes ao tartarato (Kit Sigma 387A; Sigma-Aldrich). Os pré-osteoclastos cultivados em placa Costar (Corning) de 24 poços (contendo $2 \times 10^{5}$ células/poço) foram diferençados e estimulados com FBP por $72 \mathrm{~h}$. Após esse período, o meio de cultivo foi removido e as células foram lavadas 2x com PBS e coletadas pela adição de $40 \mu 1$ de tampão de lise (Ripa Buffer, Sigma-Aldrich). Foi colocado $2 \mu 1$ da diluição contendo as células em placa de 96 poços e incubada em $200 \mu 1$ da solução corante contendo tartaratos por 30 minutos a $37^{\circ} \mathrm{C}$, ao abrigo da luz, de acordo com as instruções do fabricante. Em seguida, foi lida em espectrofotômetro na absorbância de 580 nm.

\subsubsection{Quantificação da viabilidade celular por espectrofotometria - MTT}

A proliferação/viabilidade celular foi avaliada através do método que se baseia na medida da atividade da enzima desidrogenase mitocondrial, a qual quando ativa, é capaz de metabolizar o reagente MTT (3-(4,5-dimethylthiazol-2-yl)-diphenyltetrazolium bromide). O MTT é incorporado pelas células metabolicamente ativas, produzindo cristais de formazan de cor púrpura que se acumulam no seu interior. Para isso, os pré-osteoclastos foram cultivados em placas Costar (Corning) de 96 poços (contendo 2×104 células/poço) na presença de M-CSF (30ng/ml) e RANKL (10ng/ml, R\&D System). Depois das $24 \mathrm{~h}$ de incubação, as células foram estimuladas com meio fresco contendo as duas concentrações de FBP por 1, 4 e $24 \mathrm{~h}$. Ademais, foi colocado o grupo de células controle que consistiu de meio sem a adição da FBP. Após cada período, o meio das placas foi removido, em seguida as células foram lavadas 2x com PBS e acrescentou-se 22ul de MTT (5 mg/ml; Sigma-Aldrich), depois foram 
incubadas por $3 \mathrm{~h} \mathrm{a} 37^{\circ} \mathrm{C}$. Posteriormente, esses foram solubilizados pela adição de $200 \mu \mathrm{l}$ de DMSO e lidas a $570 \mathrm{~nm}$ em espectrofotômetro. Os valores da viabilidade celular foram expressos em percentagem relativa à absorbância determinada nas células controle.

\subsubsection{Expressão dos genes marcadores de osteoclastos como Nfatc1, Trap e Catepsina K por PCR em tempo real}

Para analisar a expressão gênica, os pré-osteoclastos cultivados em placas Costar (Corning) de 24 poços (contendo $2 \times 10^{5}$ células/poço) foram diferenciados e estimulados com FBP por 72 h. Decorrido o período de estimulação, o meio de cultivo foi removido, em seguida as células foram lavadas 2x com PBS. O lisado total de células foi obtido pela adição de $175 \mu 1$ de tampão de lise (RNA Lysis Buffer + $\beta$-Mercaptoethanol, Promega). O RNA total das amostras foi obtido utilizando kit de extração SV total RNA isolation System (Promega) e o cDNA foi obtido por meio da transcrição reversa utilizando OligoDt e Random primers com o Kit de síntese de cDNA High-Capacity (Applied Biosystems), de acordo com as instruções do fabricante.

As reações de PCR para amplificação dos genes de interesse foram realizadas utilizando os respectivos primers específicos e TaqMan Universal master Mix II (Applied Biosystems). Todos os experimentos foram realizados em um equipamento do modelo StepOnePlus (Applied Biosystems, Life Technologies) usando o método do limiar do ciclo comparativo $(\mathrm{Ct})(\Delta \Delta \mathrm{Ct})$. Todas as reações foram realizadas compreendendo 40 ciclos, com etapa de desnaturação à $95^{\circ} \mathrm{C}$, anelamento e extensão à $60^{\circ} \mathrm{C}$, utilizando-se o volume final de $10 \mu 1$ por reação (Primer: 0,5 $\mu 1+$ GAPDH: $0,5 \mu 1+$ Nuclease-free water: $2 \mu 1+$ TaqMix: $5 \mu 1+$ cDNA: $2 \mu \mathrm{l})$ em placas de 96 poços. Para todas as reações em duplicata foi utilizado o GAPDH como gene de referência estável e uma amostra de referência do grupo controle para quantificação relativa. Foram utilizados primers específicos $\left(\right.$ TaqMan $^{\circledR}$ Gene Expression Assay) para os seguintes genes: Nfatcl (Mm00479445_m1), Trap (Mm00475698_m1), Catepsina K (Mm00484039_m1) e Gapdh (Mm99999915_g1).

\subsubsection{Expressão das proteínas NFATc1 e catepsina K por Western Blot}

Os pré-osteoclastos cultivados em placas Costar (Corning) de 24 poços (contendo $2 \times 10^{5}$ células/poço) foram diferenciados e estimulados com FBP por 72 h. Após esse tempo, o 
meio de cultivo foi removido, em seguida as células foram lavadas 2x com PBS. O lisado total de células foi obtido pela adição de $40 \mu$ de tampão de lise (Ripa Buffer, Sigma-Aldrich) adicionados de inibidor de protease e fosfatases II e III (Sigma-Aldrich). A concentração de proteína foi determinada pelo método colorimétrico utilizando um kit comercial (Pierce ${ }^{\circledR}$ BCA Protein Assay, Thermo Scientific). Cada amostra (contendo 10 $\mu \mathrm{g}$ de proteína total) foi aplicada em um gel de poliacrilamida com 10-15\% de SDS em cuba de eletroforese a 200v/100mA por 40 minutos. As proteínas separadas foram transferidas para uma membrana de PVDF (Immobilon-P, MerckMillipore) (100v por 1 hora). A membrana foi lavada com Tris- $\mathrm{HCl} 10 \mathrm{mM}$ contendo $\mathrm{NaCl} 150 \mathrm{mM}$ e Tween 20 0,1\% (TBS-T) e bloqueada por $1 \mathrm{~h}$ em TBS-T contendo leite desnatado a 5\%. O anticorpo primário contra cada alvo estudado (NFAT2 e catepsina $\mathrm{K}\left(\right.$ abcam $\left.^{\circledR}\right)$ ) e $\beta$-actina como controle endógeno (Sigma-Aldrich)) foi adicionado em diluição pré-determinada (1:2000, 1:3000 e 1:30000; respectivamente) em TBS-T contendo leite ou BSA a 5\%, incubando-se por aproximadamente $16-18 \mathrm{~h}$ a $4^{\circ} \mathrm{C}$. Após incubação com anticorpo secundário conjugado à peroxidase (anti-mouse 1:15000, antirabbit 1:20000 e anti-mouse 1:25000; respectivamente; $\left(\operatorname{abcam}^{\circledR}\right)$ ), a imunorreatividade das bandas foi detectada por adição de uma solução de quimiluminescência (WestPico Super Signal, Pierce). Para a análise dos resultados, os valores da densitometria das bandas para cada alvo foram normalizados pelo valor da leitura da $\beta$-actina.

\subsubsection{Avaliação da atividade dos osteoclastos}

Os pré-osteoclastos cultivados em placa de osso (Corning ${ }^{\mathrm{TM}}$ Osteo Assay Surface; Corning) de 96 poços (contendo $2 \times 10^{4}$ células/poço) foram diferenciados e estimulados com FBP por 96 h. Decorrido o período de estimulação, o meio de cultivo foi removido as células foram lavadas com água destilada, incubadas em hipoclorito de sódio 3\% por 5 minutos e novamente lavadas com água destilada. Em seguida, a atividade dos osteoclastos foi avaliada pela medida das áreas de reabsorção formadas nos poços ao estereomicroscópio.

\subsection{Determinação do mecanismo de ação da FBP na osteoclastogênese: participação da piruvato quinase M2 (PKM2)}

Para avaliar o segundo objetivo específico foi realizado o protocolo de diferenciação de osteoclastos (mencionado acima) a partir dos camundongos Lysm $^{\mathrm{Cre} /}$ (controle) e Lysm $^{\mathrm{Cre} /}$ 
$\mathrm{PKM}^{\mathrm{f} / \mathrm{f}}$ (gerados para deficiência específica do gene da PKM2 em macrófagos). As características dos osteoclastos nos dois grupos animais foram analisadas no dia 4 de diferenciação pelo ensaio histoquímico de coloração de células multinucleadas sensíveis ao TRAP, como descrito anteriormente.

\subsection{Análise Estatística}

As análises estatísticas foram realizadas com o software GraphPad Prism 5.0 (GraphPad Software, San Diego, CA), utilizando o teste- $t$ de Student bicaudal, para a comparação entre dois grupos. 


\section{RESULTADOS}




\section{RESULTADOS}

\subsection{Estudar se a estimulação com diferentes concentrações da frutose 1,6-bisfosfato (FBP), interfere na osteoclastogênese e atividade dos osteoclastos in vitro.}

\subsubsection{Efeito da FBP sobre a osteoclastogênese in vitro}

A figura 3 mostra que pré-osteoclastos cultivados por $96 \mathrm{~h}$ com M-CSF e RANKL diferenciam em osteoclastos, evidenciados por células coradas com TRAP e apresentando mais de 3 núcleos e tamanho amplo.

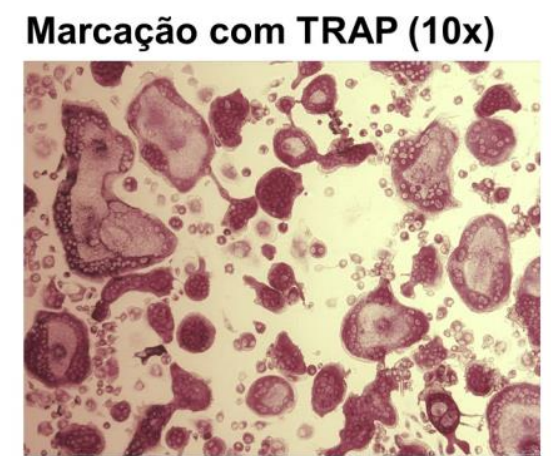

0

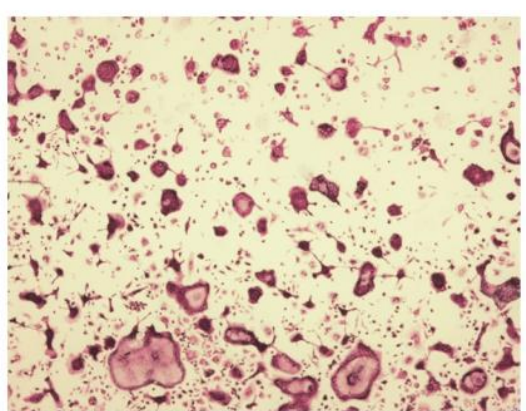

100

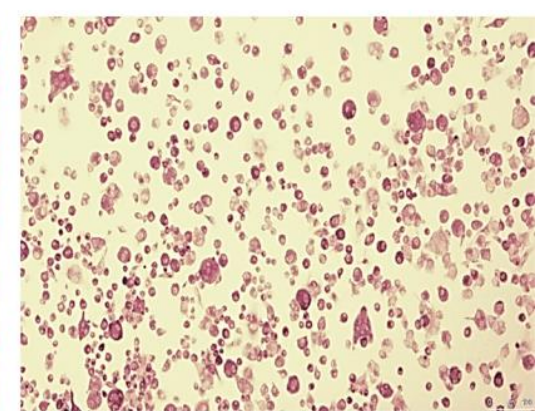

300

$\operatorname{FBP}(\mu \mathrm{M})$

Figura 3. Efeito da frutose 1,6-bifosfato (FBP) sobre a osteoclastogênese in vitro. Pré-osteoclastos foram diferenciados em osteoclastos com M-CSF (30 ng/ml) e RANKL (10 ng/ml) e diferentes concentrações de FBP $(0,100$ e $300 \mu \mathrm{M})$. Os osteoclastos foram identificados pela marcação com TRAP no tempo de $96 \mathrm{~h}$ (aumento de 10x).

Da mesma maneira, a marcação com TRAP evidenciou que os osteoclastos tratados com FBP 100 e $300 \mu \mathrm{M}$ eram de menor tamanho e exibiam menos núcleos que os osteoclastos diferenciados somente com M-CSF e RANKL (Fig. 3).

A quantificação dos osteoclastos mostra um menor número de osteoclastos $\mathrm{TRAP}^{+}$no grupo de células tratadas com FBP 100 e $300 \mu \mathrm{M}$ quando comparado com células não tratadas (Fig. 4). Além disso, a extensão dos osteoclastos tratados com as duas concentrações de FBP $(100$ e $300 \mu \mathrm{M})$ foi significativamente menor do que os osteoclastos controle. Observa-se que o tratamento como FBP $300 \mu \mathrm{M}$ provocou uma redução ainda maior na extensão dos 
osteoclastos ( $\mathrm{p}<0.0001$ ) (Fig. 5). Desta forma, as figuras 3-5 mostram que FBP inibe a diferenciação dos osteoclastos de maneira dose-dependente.

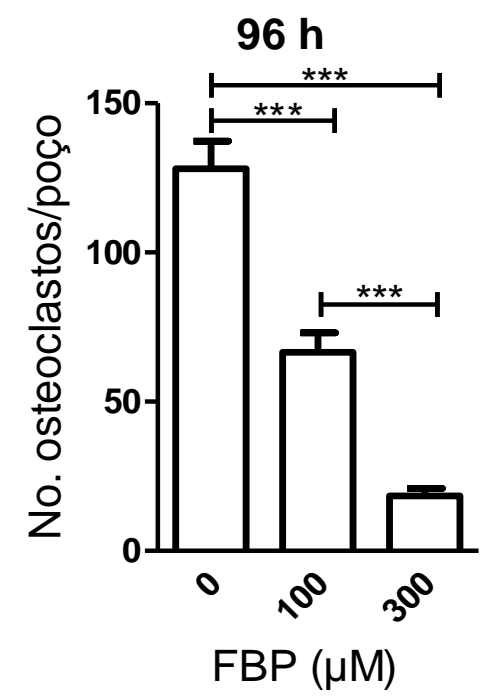

Figura 4. Número de osteoclastos formados após 96 h de diferenciação e estimulação com frutose 1,6-bifosfato (FBP). Pré-osteoclastos foram diferenciados em osteoclastos na presença de M-CSF (30 ng/ml), RANKL $(10 \mathrm{ng} / \mathrm{ml})$ e diferentes concentrações de FBP $(0,100$ e $300 \mu \mathrm{M})$. Os osteoclastos foram identificados pela marcação com TRAP no tempo de $96 \mathrm{~h}$. As células multinucleadas TRAP+ (com três ou mais núcleos) foram contadas. $(\mathrm{n}=5)$ para cada grupo. ***p $<0.0001$ (Teste- $t)$.

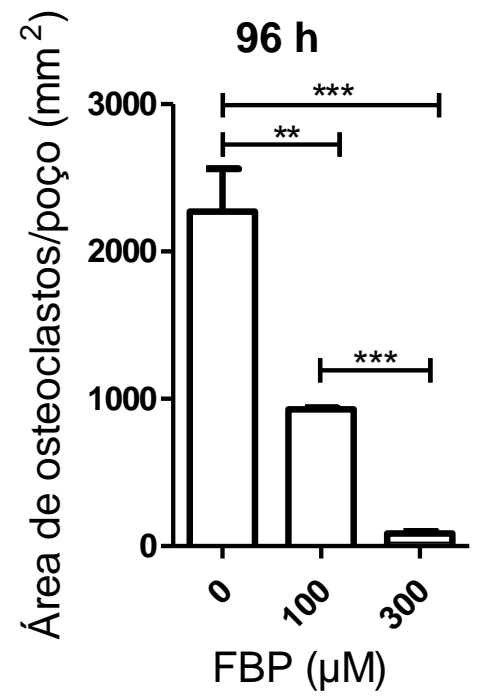

Figura 5. Área dos osteoclastos formados após 96 h de diferenciação e estimulação com frutose 1,6-bifosfato (FBP). Pré-osteoclastos foram diferenciados em osteoclastos na presença de M-CSF (30 $\mathrm{ng} / \mathrm{ml})$, RANKL $(10 \mathrm{ng} / \mathrm{ml})$ e diferentes concentrações de FBP $(0,100$ e $300 \mu \mathrm{M})$. Os osteoclastos foram identificados pela marcação com TRAP no tempo de $96 \mathrm{~h}$. As células multinucleadas TRAP+ (com três ou mais núcleos) foram contadas. $(\mathrm{n}=5)$ para cada grupo. ${ }^{* *} \mathrm{p}<0.01$, *** $\mathrm{p}<0.0001$ (Teste$t)$. 


\subsubsection{Efeito da FBP sobre a atividade de TRAP no lisado celular de osteoclastos}

No intuito de avaliar o efeito da FBP sobre a atividade de TRAP no lisado celular, os pré-osteoclastos foram diferenciados y estimulados com FBP por $72 \mathrm{~h}$. Decorrido o período de diferenciação, o lisado de células foi obtido e a atividade de TRAP foi avaliada por espectrofotometria. O tratamento com $100 \mu \mathrm{M}$ de FBP induziu uma redução significativa na atividade enzimática de TRAP no lisado celular dos osteoclastos, quando comparado com o lisado celular dos não tratados (Fig. 6). Observa-se também na figura 6, que a diminuição na atividade de TRAP no lisado de osteoclastos estimulados com FBP $300 \mu \mathrm{M}$ foi ainda maior. Desse modo, FBP reduz a atividade de TRAP no lisado celular de osteoclastos de maneira dose-dependente.

$72 \mathrm{~h}$

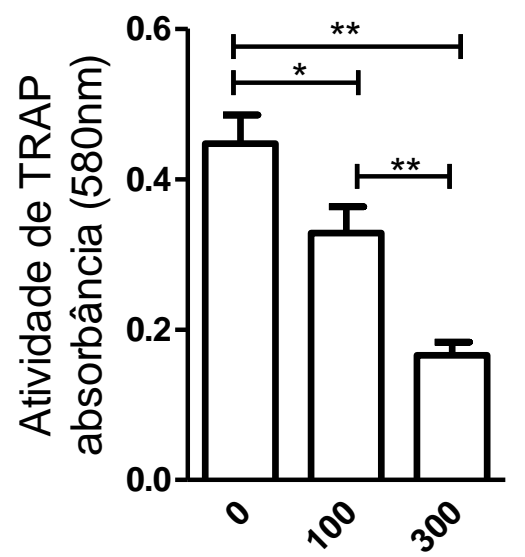

$\operatorname{FBP}(\mu \mathrm{M})$

Figura 6. Efeito da frutose 1,6-bifosfato (FBP) sobre a atividade de TRAP no lisado celular de osteoclastos. Pré-osteoclastos foram diferenciados em osteoclastos na presença de M-CSF (30 ng/ml), RANKL $(10 \mathrm{ng} / \mathrm{ml})$ e diferentes concentrações de FBP $(0,100$ e $300 \mu \mathrm{M})$. A atividade de TRAP no lisado celular de osteoclastos foi identificada pelo ensaio espectrofotométrico no tempo de $72 \mathrm{~h}$. (n= 5) para cada grupo. $* \mathrm{p}<0.05,{ }^{* *} \mathrm{p}<0.01($ Teste- $t)$.

\subsubsection{Efeito da FBP sobre a viabilidade celular}

Com a finalidade de determinar se as concentrações utilizadas de FBP (100 e $300 \mu \mathrm{M})$ ocasionavam um efeito tóxico nos osteoclastos, a viabilidade celular foi quantificada pelo ensaio de MTT. Observou-se uma leve redução da viabilidade no tempo de $1 \mathrm{~h}$ e 4 h quando incubados os osteoclastos com FBP $100 \mu \mathrm{M}$, contudo a porcentagem de células em proliferação na presença da FBP foi em torno de 78\%, para ambos (Fig. 7a, b). 
No entanto, o estímulo com $300 \mu \mathrm{M}$ de FBP induziu um leve aumento na proliferação celular no tempo de 24 h (Fig. 7c). Estes dados mostram que existe um efeito inibitório de FBP $(100 \mu \mathrm{M}$ e $300 \mu \mathrm{M})$ na diferenciação de osteoclastos e que não é devido a seu efeito tóxico sobre este tipo celular (Fig. 7a-c).

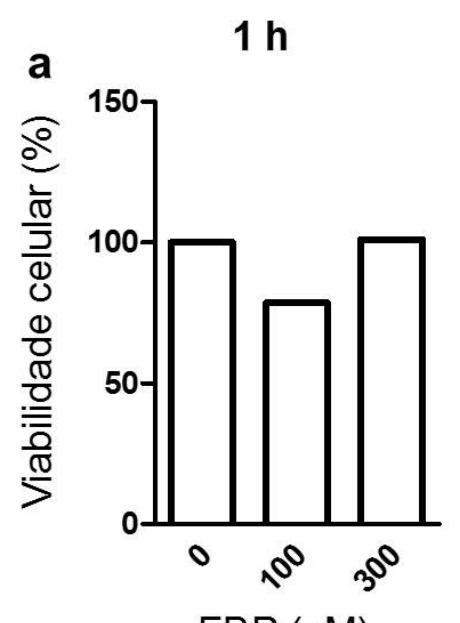

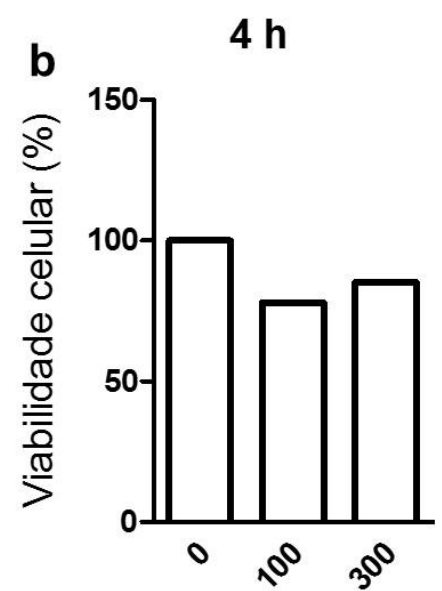

$\operatorname{FBP}(\mu \mathrm{M})$

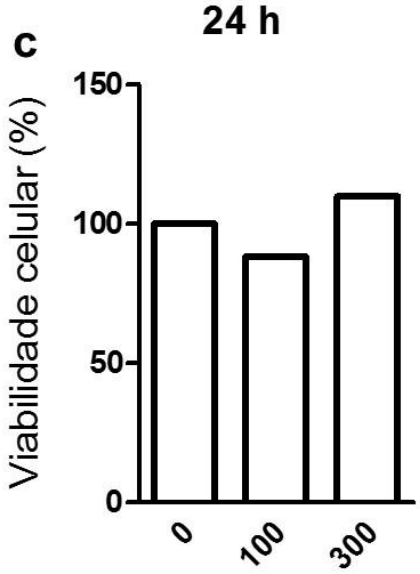

$\operatorname{FBP}(\mu \mathrm{M})$

Figura 7. Efeito da frutose 1,6-bifosfato (FBP) sobre a viabilidade celular. Osteoclastos foram estimulados na presença de FBP $(0,100$ e $300 \mu \mathrm{M})$. A citotoxicidade foi avaliada através do ensaio de MTT após (a) $1 \mathrm{~h},(\mathrm{~b}) 4 \mathrm{~h}, \mathrm{e}(\mathrm{c}) 24 \mathrm{~h}$ de tratamento. $(\mathrm{n}=4)$ para cada grupo.

\subsubsection{Efeito da FBP sobre a expressão relativa de RNAm de Nfatc1, Trap e Catepsina $K$ nos osteoclastos.}

Considerando que os osteoclastos se fundem e diferenciam em $96 \mathrm{~h}$ de incubação com M-CSF e RANKL, foi avaliado por PCR em tempo real o efeito da FBP sobre a expressão gênica de marcadores osteoclastogênicos em tempos anteriores a sua diferenciação.

O fator de transcrição NFATc1, apresenta um papel importante na osteoclastogênese, e regula a expressão desses marcadores, como por exemplo dos envolvidos na diferenciação e função celular. Dessa maneira, após 72 h de diferenciação, foi observado que os osteoclastos tratados com FBP $100 \mu \mathrm{M}$ expressaram níveis de RNAm de Nfatc1 menores em comparação com os não tratados (Fig. 8). Semelhantemente, a figura 8 mostra que na presença de FBP 300 $\mu \mathrm{M}$ a redução nos níveis de RNAm de $N f a t c 1$ foi significativamente maior $(* * \mathrm{p}<0.01)$. 
$72 \mathrm{~h}$

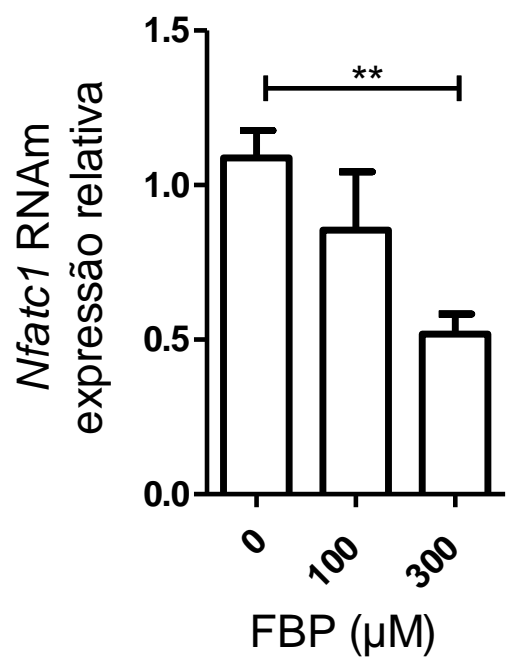

Figura 8. Efeito da frutose 1,6-bifosfato (FBP) sobre a expressão relativa de RNAm de $\mathbf{N}$ fatc1. Pré-osteoclastos foram diferenciados em osteoclastos na presença de M-CSF (30 ng/ml), RANKL (10 $\mathrm{ng} / \mathrm{ml})$ e diferentes concentrações de $\operatorname{FBP}(0,100$ e $300 \mu \mathrm{M})$. A expressão de RNAm foi avaliada através de qRT-PCR no tempo de $72 \mathrm{~h}$. $(\mathrm{n}=3)$ para cada grupo. $* * \mathrm{p}<0.01$ (Teste- $t)$.

Uma vez demonstrada a redução nos níveis de RNAm de $N f a t c l$ após tratamento com FBP, foi avaliada a expressão génica de Trap, um marcador de diferenciação de osteoclastos. Encontrou-se igualmente, que a adição de FBP $100 \mu \mathrm{M}$ no meio de cultivo diminuiu significativamente a expressão relativa de RNAm de Trap nos osteoclastos quando comparados com os controles; e ao adicionar $300 \mu \mathrm{M}$ da FBP, a redução na expressão foi ainda mais significativa (Fig. 9).

\section{$72 \mathrm{~h}$}

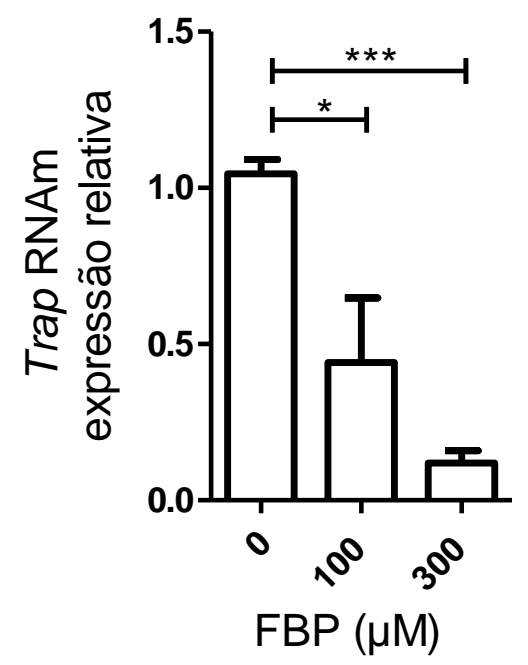

Figura 9. Efeito da frutose 1,6-bifosfato (FBP) sobre a expressão relativa de RNAm de Trap. Préosteoclastos foram diferenciados em osteoclastos na presença de M-CSF (30 ng/ml), RANKL (10 $\mathrm{ng} / \mathrm{ml})$ e diferentes concentrações de $\operatorname{FBP}(0,100$ e $300 \mu \mathrm{M})$. A expressão de RNAm foi avaliada através de qRT-PCR no tempo de $72 \mathrm{~h}$. $(\mathrm{n}=3)$ para cada grupo. ${ }^{*} \mathrm{p}<0.05, * * * \mathrm{p}<0.0001$ (Teste- $\left.t\right)$. 
A fim de determinar se produto da diminuição na expressão gênica do fator $N f a t c 1$ e do marcador de diferenciação (Trap), a expressão do marcador de atividade osteoclástica também estava comprometida, foram avaliados os níveis de RNAm de Catepsina $K$. Como esperado, o qPCR evidenciou que ao final de $72 \mathrm{~h}$ de cultura, os osteoclastos tratados com FBP $(100$ e $300 \mu \mathrm{M})$ expressaram níveis de RNAm de Catepsina $K$ significativamente menores em comparação com os não tratados (Fig. 10). Conjunto, as figuras 8-10 mostram que o estímulo com 100 e $300 \mu \mathrm{M}$ de FBP promove uma diminuição, dose-dependente na expressão gênica do fator regulador NFATc1, e por conseguinte, uma redução na expressão gênica dos marcadores de diferenciação (TRAP) e de atividade de osteoclastos (catepsina K).

$72 \mathrm{~h}$

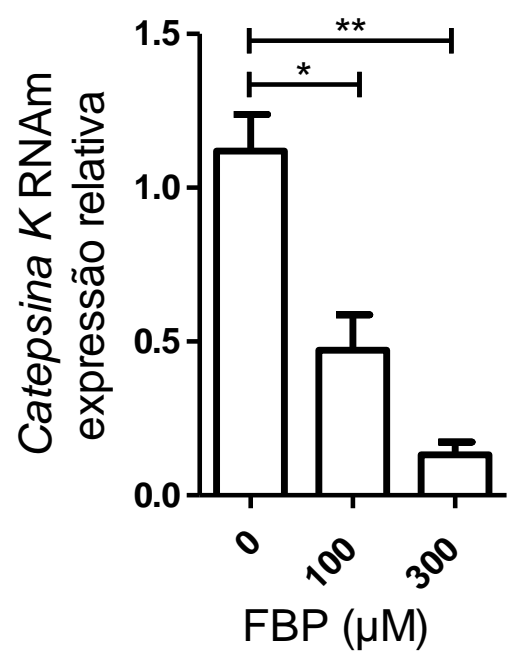

Figura 10. Efeito da frutose 1,6-bifosfato (FBP) sobre a expressão relativa de RNAm de Catepsina K. Pré-osteoclastos foram diferenciados em osteoclastos na presença de M-CSF (30 ng/ml), RANKL $(10 \mathrm{ng} / \mathrm{ml})$ e diferentes concentrações de $\operatorname{FBP}(0,100$ e $300 \mu \mathrm{M})$. A expressão de RNAm foi avaliada através de qRT-PCR no tempo de $72 \mathrm{~h}$. $(\mathrm{n}=3)$ para cada grupo. ${ }^{*} \mathrm{p}<0.05$, ** $\mathrm{p}<0.01$ (Teste$t$ ).

\subsubsection{Efeito da FBP sobre os níveis de proteína de NFATc1 e catepsina $K$ nos osteoclastos}

Para avaliar se o efeito da FBP era transcricional, os níveis de proteína nos osteoclastos diferenciados e estimulados por $72 \mathrm{~h}$ foram determinados por Western Blot.

Conforme representado na figura 11, os osteoclastos diferenciados na presença de FBP $100 \mu \mathrm{M}$ apresentaram uma diminuição significativa nos níveis de proteína do fator NFATc1 quando comparados com osteoclastos diferenciados na ausência de FBP. Observou-se uma 
redução significativamente maior nos níveis de proteína quando diferenciados na presença de FBP $300 \mu \mathrm{M}$ (Fig. 11).

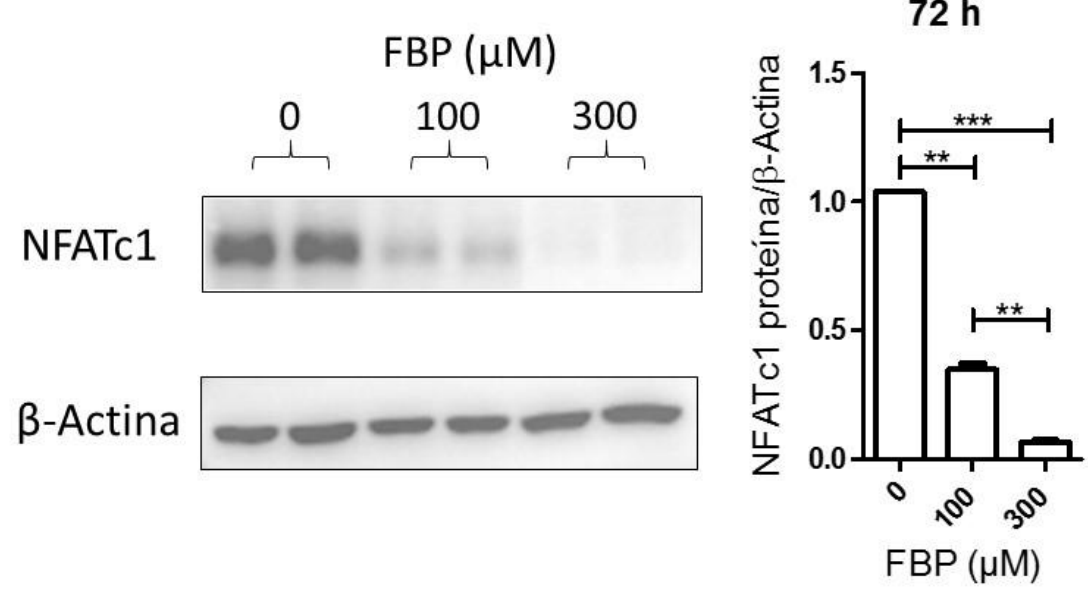

Figura 11. Efeito da frutose 1,6-bifosfato (FBP) sobre a expressão da proteína NFATc1 nos osteoclastos. Pré-osteoclastos foram diferenciados em osteoclastos na presença de M-CSF (30 ng/ml), RANKL (10 ng/ml) e diferentes concentrações de FBP $(0,100$ e $300 \mu \mathrm{M})$. A expressão de proteína foi avaliada através de Western Blot no tempo de 72 h. $(\mathrm{n}=2)$ para cada grupo. **p $<0.01$, *** p < 0.0001 (Teste- $t$ ).

Como observado anteriormente, o tratamento com $\mathrm{FBP}(0,100$ e $300 \mu \mathrm{M})$ foi capaz de reduzir significativamente e de forma dose-dependente, os níveis de proteína de catepsina $\mathrm{K}$ nos osteoclastos quando comparados com osteoclastos não tratados (Fig. 12). Esses resultados demostram que além da redução na expressão gênica, a FBP induz uma diminuição significativa nos níveis de proteína do fator NFATc1, e consequentemente na expressão proteica do marcador de função osteoclástica, catepsina K. (Fig. 11 e 12).

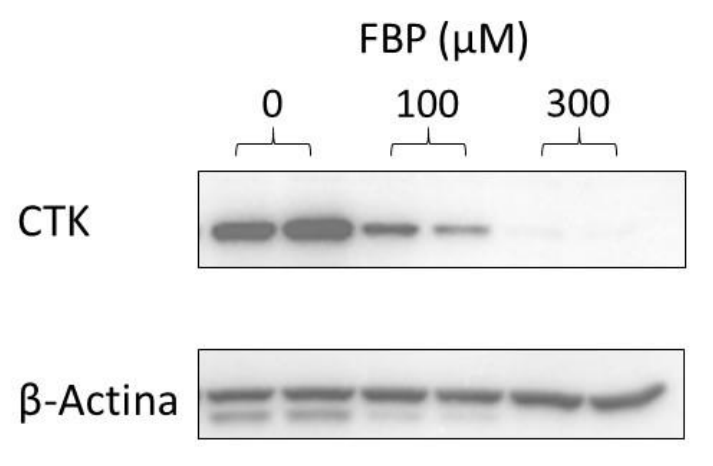

$72 \mathrm{~h}$

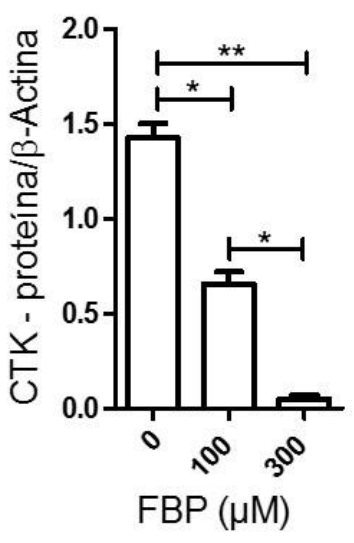

Figura 12. Efeito da frutose 1,6-bifosfato (FBP) sobre a expressão da proteína catepsina $K$ (CTK) nos osteoclastos. Pré-osteoclastos foram diferenciados em osteoclastos na presença de M-CSF (30 ng/ml), RANKL (10 ng/ml) e diferentes concentrações de FBP $(0,100$ e $300 \mu \mathrm{M})$. A expressão de proteína foi avaliada através de Western Blot no tempo de $72 \mathrm{~h}$. (a) Expressão de proteína $(\mathrm{n}=2)$ para cada grupo. $* \mathrm{p}<0.05, * * \mathrm{p}<0.01$ (Teste- $t$ ). 


\subsubsection{Efeito da FBP sobre a atividade ósteo-reabsortiva dos osteoclastos}

O conjunto de resultados demonstrados até o momento sugerem que FBP promove uma inibição na osteoclastogênese de maneira dose-dependente. Para confirmar, se o estímulo com as duas concentrações de FBP $(100$ e $300 \mu \mathrm{M})$ afetava também a atividade de reabsorção óssea deste tipo celular, os pré-osteoclastos foram diferenciados e estimulados em placa de osso (Corning TM Osteo Assay Surface; Corning) por 96 h. Transcorrido o período de incubação, a função dos osteoclastos foi avaliada pela medida das áreas de reabsorção formadas na camada de hidroxiapatita aderida no fundo dos poços.

A figura 13a, representa a capacidade funcional dos osteoclastos diferenciados com M-CSF e RANKL na ausência de FBP, sendo evidenciada pelas amplas áreas de reabsorção (em branco) formadas na camada de hidroxiapatita ao final do período de incubação.

Observou-se que na presença de FBP $100 \mu \mathrm{M}$ as áreas de reabsorção formadas pelos osteoclastos diminuíram com respeito as áreas formadas por os osteoclastos diferenciados somente com M-CSF e RANKL (Fig. 13b). Já com a adição de FBP $300 \mu$ M a redução nas áreas de reabsorção foi ainda maior (Fig. 13c).

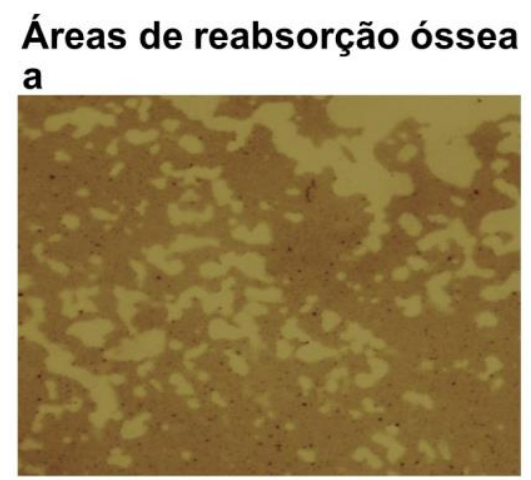

0

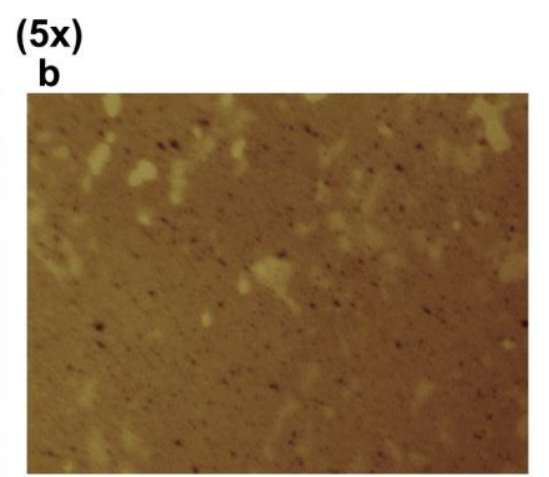

100

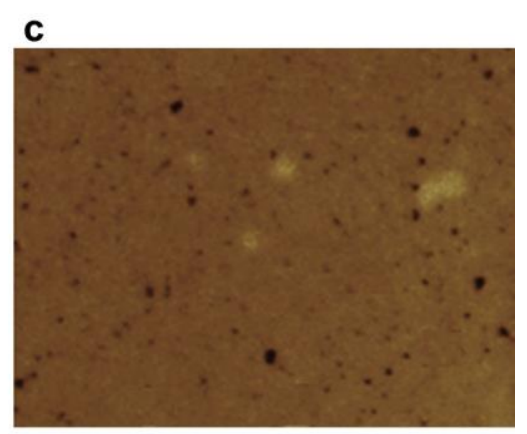

300

$\operatorname{FBP}(\mu \mathrm{M})$

Figura 13. Áreas de reabsorção óssea formadas pelos osteoclastos diferenciados com M-CSF e RANKL na presença da frutose 1,6-bifosfato (FBP). Pré-osteoclastos foram diferenciados em osteoclastos com M-CSF (30 ng/ml) e RANKL (10 ng/ml) e diferentes concentrações de FBP (100 e $300 \mu \mathrm{M}$ ), em placas de osso (Corning ${ }^{\mathrm{TM}}$ Osteo Assay Surface). A atividade foi determinada no tempo de $96 \mathrm{~h}$ pelas áreas de reabsorção formadas (indicadas em branco) na camada de hidroxiapatita aderida no poço (aumento de $5 \mathrm{x}$ ). 
Por conseguinte, com a quantificação das área de reabsorção óssea formadas pelos osteoclastos, é possível sugerir que o estímulo com $\mathrm{FBP}(0,100$ e $300 \mu \mathrm{M})$ também é capaz de reduzir a capacidade funcional deste tipo celular de maneira dose-dependente, sendo a redução significativa com a concentração de $300 \mu \mathrm{M}$ (Fig. 14).

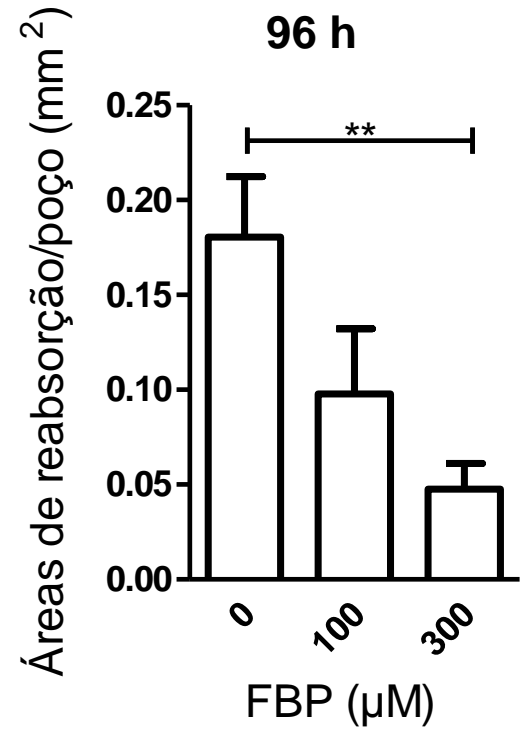

Figura 14. Quantificação das área de reabsorção/poço formadas pelos osteoclastos diferenciados com M-CSF e RANKL na presença da frutose 1,6-bifosfato (FBP). Pré-osteoclastos foram diferenciados em osteoclastos na presença de M-CSF (30 ng/ml), RANKL (10 ng/ml) e diferentes concentrações de FBP $(0,100$ e $300 \mu \mathrm{M})$, em placas de osso (Corning ${ }^{\mathrm{TM}}$ Osteo Assay Surface). A atividade foi determinada no tempo de $96 \mathrm{~h}$ pela medida das áreas de reabsorção formadas na camada de hidroxiapatita aderida no poço. $(\mathrm{n}=4)$ para cada grupo. $* * \mathrm{p}<0.01($ Teste- $t)$.

\subsection{Determinar o mecanismo de ação da FBP na osteoclastogênese: participação da piruvato quinase M2 (PKM2).}

FBP é um ativador alostérico da piruvato quinase M2 (PKM2), uma enzima que participa da etapa final da glicólise, originando ATP e piruvato a partir de seu substrato fosfoenolpiruvato (PEP). A PKM2 regula processos que demandam altos níveis de energia (ATP), principalmente os relacionados com a diferenciação e proliferação celular. Em vista disso e com a comprovação de que FBP inibe a osteoclastogênese e atividade reabsortiva óssea dessas células, o passo seguinte foi determinar se a PKM2 estaria envolvida nesse efeito inibidor da FBP. Para isso, os pré-osteoclastos obtidos da medula óssea de camundongos Lysm $^{\text {Cre/- }}$ (controle) e Lysm ${ }^{\text {Cre/- }}$ PKM2 $^{\text {f/f }}$ (gerados para deficiência específica do gene da PKM2 em macrófagos) foram diferenciados e estimulados por $96 \mathrm{~h}$. Decorrido esse tempo, as 
características dos osteoclastos nos dois grupos animais foram analisadas pela marcação com TRAP.

Conforme tem sido evidenciado, a figura 15 mostra que tanto para os animais deficientes quanto para os controle, o estímulo com $\operatorname{FBP}(0,100$ e $300 \mu \mathrm{M})$ promoveu uma diminuição dose-dependente no número de osteoclastos. Porém, não se observou diferença no número de osteoclastos formados, quando comparados simultaneamente os grupos experimentais $\left(0,100\right.$ e 300) dos camundongos Lysm ${ }^{\mathrm{Cre} /} \mathrm{PKM}^{\mathrm{f} / \mathrm{f}}$ e $\operatorname{dos} \mathrm{Lysm}^{\mathrm{Cre} /}$ (Fig. 15).

\section{$96 \mathrm{~h}$}

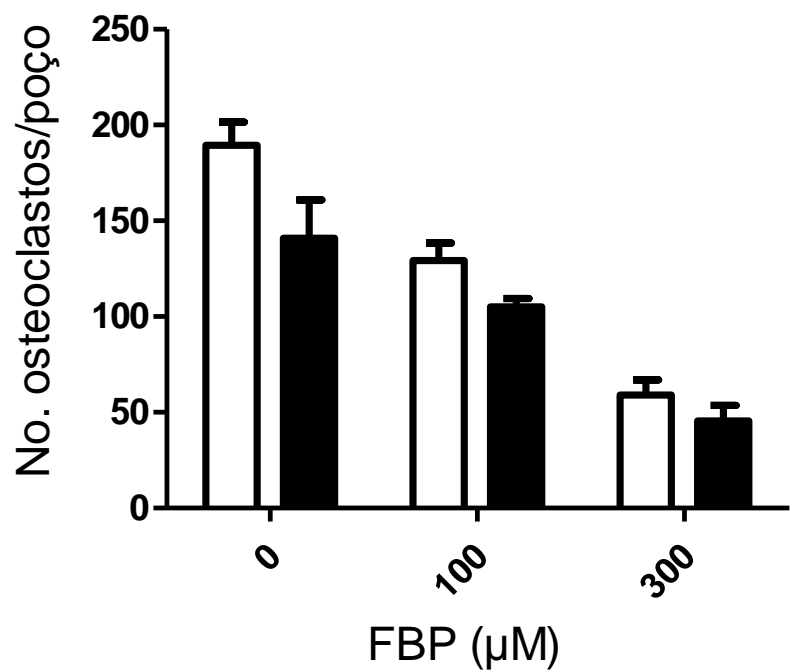

Figura 15. Número de osteoclastos formados após 96 h de diferenciação e estimulação com frutose 1,6-bifosfato (FBP), a partir de camundongos $\mathrm{Lysm}^{\mathrm{Cre} /}$ PKM2 ${ }^{\mathrm{f} / \mathrm{f}}$ e dos $\mathrm{Lysm}^{\mathrm{Cre} /}$. Préosteoclastos provenientes da medula óssea de camundongos $\mathrm{Lysm}^{\mathrm{Cre} /-}$ (controle) e $\mathrm{Lysm}^{\mathrm{Cre} /-} \mathrm{PKM} 2^{\mathrm{f} / \mathrm{f}}$ (gerados para deficiência específica do gene da PKM2 em macrófagos) foram diferenciados em osteoclastos na presença de M-CSF (30 ng/ml), RANKL (10 ng/ml) e diferentes concentrações de FBP $(0,100$ e $300 \mu \mathrm{M})$. Os osteoclastos foram identificados pela marcação com TRAP no tempo de $96 \mathrm{~h}$. As células multinucleadas TRAP+ (com três ou mais núcleos) foram contadas. $(n=4)$ para cada grupo.

Do mesmo modo, nos dois grupos animais a extensão dos osteoclastos tratados com as duas concentrações de FBP $(100$ e $300 \mu \mathrm{M})$ foi significativamente menor quando comparado com os controle. (Fig. 16). No entanto, a figura 16 mostra que não existe diferença na extensão dos osteoclastos formados, quando comparados simultaneamente os grupos experimentais $\left(0,100\right.$ e 300) dos camundongos $\mathrm{PKM}^{\mathrm{f} / \mathrm{f}}$ e dos Lysm $^{\text {Cre/- }}$. Esses resultados evidenciam que na ausência e presença de PKM2, o estímulo com FBP $(0,100$ e $300 \mu \mathrm{M})$ promove uma diminuição dose-dependente no número e tamanho de osteoclastos de forma similar, então sugerindo que o efeito inibidor da FBP sobre a osteoclastogênese e reabsorção óssea não envolve a PKM2 (Fig. 15 e 16). 


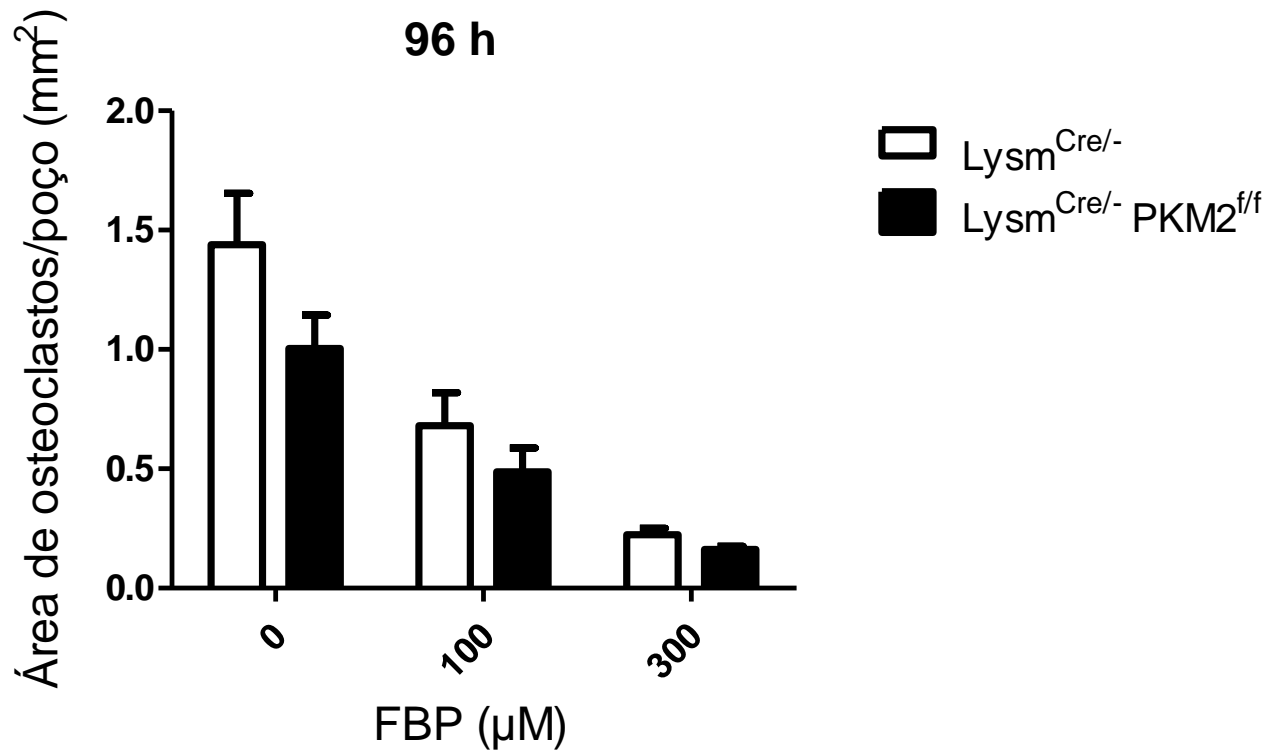

Figura 16. Área de osteoclastos formados após $96 \mathrm{~h}$ de diferenciação e estimulação com frutose 1,6-bifosfato (FBP), a partir de camundongos $\mathrm{Lysm}^{\mathrm{Cre} /} \mathrm{PKM}^{\mathrm{f} / \mathrm{f}}$ e $\operatorname{dos}_{\mathrm{Lysm}}{ }^{\mathrm{Cre} /}$. . Pré-osteoclastos provenientes da medula óssea de camundongos Lysm ${ }^{\text {Cre/- }}$ (controle) e Lysm ${ }^{\text {Cre/- }} \mathrm{PKM}^{\mathrm{fff}}$ (gerados para deficiência específica do gene da PKM2 em macrófagos) foram diferenciados em osteoclastos na presença de M-CSF (30 ng/ml), RANKL (10 ng/ml) e diferentes concentrações de FBP $(0,100$ e 300 $\mu \mathrm{M})$. Os osteoclastos foram identificados pela marcação com TRAP no tempo de $96 \mathrm{~h}$. As células multinucleadas TRAP+ (com três ou mais núcleos) foram contadas. $(\mathrm{n}=4)$ para cada grupo. 
DISCUSSÃO 


\section{DISCUSSÃO}

A osteoclastogênese tem sido demostrada como um processo de alto gasto energético regulado por diferentes fatores. Deste modo, o presente trabalho considerou num primeiro nível a participação da frutose 1,6-bisfosfato (FBP) na formação e atividade dos osteoclastos, fornecendo evidências importantes. Posto que, a diferenciação de pré-osteoclastos com diferentes concentrações de FBP (100 e $300 \mu \mathrm{M})$, inibiu de forma dose-dependente a osteoclastogênese induzida por RANKL. Aquela inibição na diferenciação foi evidenciada pela diminuição do número e tamanho de células multinucleadas formadas ao final do tempo de cultura. A presença de FBP $(300 \mu \mathrm{M})$ na cultura fez com que a diminuição fosse ainda mais significativa.

A atividade de TRAP é uma característica importante que avalia a formação de osteoclastos. Á vista disso, foi também demonstrado que a FBP promove uma redução significativa na atividade de TRAP nos osteoclastos estimulados quando comparados com os não estimulados.

O ensaio de MTT é um dos indicadores colorimétricos mais utilizados para determinar o efeito citotóxico de qualquer composto e se baseia na capacidade das células viáveis reduzirem enzimáticamente o sal de tetrazólio (Mosmann, 1983). Com isso, no presente estudo, a avaliação da proliferação celular indicou que esse efeito inibidor da FBP sobre a osteoclastogênese não compromete a viabilidade dessas células. Os resultados de Donohoe e colaboradores (2001) mostraram um aumento na viabilidade de neurônios quando foram incubados com FBP. Igualmente, a FBP tem sido administrada em seres humanos sem apresentar reações adversas (Karaça et al., 2002; Markov et al., 2000; Riedel et al., 2004).

Como é sabido, a ligação RANK-RANKL induz a ativação de diferentes vias de sinalização intracelular, incluindo a via de NFATc1 (Iwamoto et al., 2004). O NFATc1 é considerado o principal fator regulador da osteoclastogênese e modula a expressão de genes envolvidos nos diferentes estágios de formação dos osteoclastos, tais como TRAP (marcador de diferenciação) e catepsina K (marcador de atividade) (Yavropoulou \& Yovos, 2008). Diante disso, os resultados deste estudo evidenciaram que o estímulo com FBP (100 e 300 $\mu \mathrm{M})$ promove uma redução dose-dependente na expressão gênica de NFATc1 e consequentemente na expressão gênica dos marcadores de osteoclastogênese e atividade, TRAP e catepsina K, respetivamente. E para confirmar que o efeito da FBP não seja só uma redução na expressão do RNA mensageiro, foi visto que essas concentrações igualmente provocam uma diminuição significativa na expressão das proteínas NFATc1 e catepsina K 
nos osteoclastos estimulados, em comparação com células diferenciadas somente com M-CSF e RANKL.

Em conjunto com o mencionado acima, a função de reabsorção óssea dos osteoclastos depende da expressão de vários genes, incluindo TRAP e catepsina K. A catepsina K é a enzima proteolítica mais abundante nas lacunas de reabsorção e junto com TRAP são essenciais para a desmineralização e degradação da matriz orgânica (Boonen et al., 2012). Por consequência, a avaliação da atividade osteoclástica confirmou que a administração exógena de FBP $(100$ e $300 \mu \mathrm{M})$ afeta de forma dose-dependente a função reabsortiva deste tipo celular, sendo evidenciado pela diminuição significativa nas áreas de reabsorção óssea formadas pelos osteoclastos submetidos ao tratamento quando comparados com os controles.

Ainda que não existam estudos descrevendo o papel da FBP na diferenciação e atividade dos osteoclastos, existem poucos trabalhos publicados até o momento que ressaltam a importância das moléculas envolvidas em vias metabólicas como a glicólise, na regulação da demanda energética para a osteoclastogênese e atividade osteoclástica. Sabe-se que osteoclastos maduros demandam altos níveis de ATP para a biossíntese dos diferentes constituintes utilizados durante a reabsorção óssea (Kim et al., 2007). Assim, foi demonstrado que níveis elevados de glicose no meio de cultura aumentam a diferenciação dos osteoclastos, enquanto a deprivação de glicose no meio de cultura, inibe a capacidade de reabsorção destas células (Indo et al., 2013). O trabalho de Oh e colaboradores (2015) evidenciou que a insulina regula a diferenciação e fusão de osteoclastos pela indução do fator de transcrição NFATc1. Da mesma maneira, a ativação da enzima LDH (lactato desidrogenase) responsável pela conversão do piruvato em lactato, facilita a maturação de osteoclastos através de NFATc1 (Ahn et al., 2016). Idem, uma pequena fração de piruvato é suficiente para estimular a osteoclastogênese (Fong et al., 2013). Dentro deste cenário metabólico, resultados prévios do nosso grupo de pesquisa, demonstraram que a chemerin, potencializa a capacidade de reabsorção dos osteoclastos por um mecanismo que envolve a fosforilação do ERK5 (RamosJunior et al., 2016). A adipocina chemerin regula a diferenciação e metabolismo de adipócitos, a qual; da mesma forma, participa na sensibilidade à insulina e homeostase da glicose (Goralski et al., 2007).

Essa diferença entre o efeito da FBP com o efeito dos outros metabólitos da via glicolítica, pode ser explicada pelo fato de que a FBP tem sido provada como um agente regulador/protetor em diversos mecanismos teciduais, como por exemplo no tratamento de doenças associadas com modificações na densidade mineral óssea. Ma e colaboradores (2012) demonstraram que a combinação de frutose 1,6-bisfosfato com estrôncio (FBP-Sr) resultou 
ser um composto seguro e efetivo para o tratamento da osteoporose pós-menopáusica in vivo, em parte, pela regulação da via OPG/RANKL/RANK. Da mesma maneira, a administração exógena da FBP atenuou marcadamente a artrite experimental, mediante a redução do infiltrado neutrofílico, da hipernocicepção e edema articular (Veras et al., 2015). Por outro lado, o trabalho de Viacava (2015) mostrou que o tratamento com $300 \mu \mathrm{M}$ da FBP (a mesma concentração usada neste estudo) provocou um aumento altamente significativo na produção da citocina anti-inflamatória IL-10 em macrófagos derivados de medula ativados com LPS. À vista disso, a relevância que tem obtido a FBP em termos de proteção pode estar relacionada à sua natureza endógena. Além disso, FBP induz a absorção de cálcio e modula o metabolismo ósseo (Alva et al., 2106; Tenenbaum \& Palangio, 1987).

Considerando que este intermediário glicolítico natural tem sido identificado como um composto seguro com diversos efeitos farmacológicos (PubChem Compd Database), alguns pesquisadores tem se empenhado em identificar novos medicamentos com eficácia terapêutica e baixa toxicidade para tratamento de doenças relacionadas à perda óssea, estudando particularmente, as substâncias naturais (Al Mamun et al., 2015; Bao et al., 2011). Neste sentido, evidências recentes demostraram que o Xanthohumol (XN) um dos flavonóides encontrado na flor do lúpulo, inibe a osteoclastogênese e reabsorção óssea in vitro e in vivo, através da supressão da interação RANK/TRAF6 e do bloqueio de NFATc1. Tendo como resultado uma inibição na expressão de genes marcadores de osteoclastogênese, incluindo TRAP, CTR e CTK (Li et al., 2015). Assim mesmo, o Cistanoside A (extrato isolado da planta $C$. deserticola) tem efeito antiosteoporótico em animais ovariectomizados, produzido pela inativação do fator NF-kB mediada por TRAF6 (Xu X et al., 2017). Estes dados sugerem portanto, que a FBP apresenta um grande potencial de, no futuro, ser incluída como um promissor agente para tratamento destas doenças.

No limite do nosso conhecimento, o mecanismo pelo qual a FBP pode induzir o efeito protetor ainda não está bem esclarecido. Contudo, alguns trabalhos sugerem a participação de diversas vias que controlam a diferenciação, proliferação sobrevivência celular como um mecanismo regulador. Em tal caso, Park e colaboradores (2004) comprovaram que os efeitos neuroprotetores da FBP dependem das vias MAPK/ERK e p38. Idem, durante a hipóxia a FBP origina uma série de sinais para a sobrevivência celular, que incluem um aumento na fosforilação do ERK (Fahlman et al., 2002).

Sabe-se que a FBP é um ativador alostérico da piruvato quinase M2 (PKM2), uma das quatro isoformas da enzima piruvato quinase (PK) (Dombrauckas et al., 2005). Esta enzima participa da última etapa da via glicolítica, catalisando a transformação do fosfoenolpiruvato 
(PEP) e ADP em piruvato e ATP, e demonstrou ser essencial nas células que utilizam a glicólise como principal fonte de energia para o processo de proliferação (Gupta \& Bamezai, 2010). Por esse motivo, nos últimos anos aumentou-se o interesse em avaliar a participação de PKM2 nos mecanismos relacionados com câncer e inflamação (Shirai et al., 2016; Wong et al., 2015; Yang et al., 2012). De acordo com Jiang e colaboradores (2014), PKM2 é importante para a segregação cromossômica e progressão da mitose em células tumorais. No entanto, a correlação entre PKM2, osteoclastogênese e reabsorção óssea ainda não está reportada.

Desse modo e para comprovar aqui se o mecanismo pelo qual a FBP inibe a osteoclastogênese seria via ativação de PKM2, os pré-osteoclastos originados de camundongos Lysm ${ }^{\mathrm{Cr} /-}$ (controle) e Lysm ${ }^{\mathrm{Cre} /-} \mathrm{PKM}^{\mathrm{f} / \mathrm{f}}$ (gerados para deficiência específica do gene da PKM2 em macrófagos) foram diferenciados e estimulados com FBP (100 e $300 \mu \mathrm{M})$ por 96 h. Decorrido o período de diferenciação, a marcação com TRAP demonstrou que o tratamento com FBP diminuiu a osteoclastogênese de maneira dose-dependente nos dois grupos animais $\left(\mathrm{Lysm}^{\mathrm{Cre} /-}\right.$ e Lysm $\left.{ }^{\mathrm{Cre} /-} \mathrm{PKM} 2^{\mathrm{f} / \mathrm{f}}\right)$. No entanto, não foi observada diferença no número e extensão dos osteoclastos quando foram comparados simultaneamente os grupos experimentais dos animais deficientes para PKM2 e dos controles.

Mesmo que não há relatos na literatura sobre o papel da PKM2 na osteoclastogênese, foi demonstrado que a deleção da PKM2 (camundongos PKM2 $2^{\text {flox/flox }}$ ) promove uma diminuição significativa na proliferação de fibroblastos embrionários quando comparados com células originadas de camundongos não deficientes (Lunt et al., 2015). Por sua parte, Spoden e colaboradores (2009) evidenciaram que em concentrações normais de glicose, a inibição da PKM2 induz uma redução significativa na proliferação celular, enquanto ante a privação de glicose, a inibição da PKM2 promove um aumento na proliferação.

Sendo assim, com os resultados deste estudo é plausível considerar que o efeito inibidor da FBP sobre a diferenciação e função reabsortiva dos osteoclastos não depende da atividade da PKM2. Não obstante, essa hipótese necessita de maiores investigações, e dessa maneira elucidar a participação da PKM2 na diferenciação deste tipo celular.

Em síntese, neste primeiro passo foi demonstrado o papel regulador da FBP na formação e função dos osteoclastos in vitro. Futuros estudos in vivo serão necessários para validar esses resultados e esclarecer o mecanismo pelo qual a FBP provoca o efeito inibidor sobre a osteoclastogênese e reabsorção óssea. 
CONCLUSÕES 


\section{CONCLUSÕES}

1) A adição de concentrações crescentes da FBP no meio de cultivo diminuem significativamente a diferenciação e atividade reabsortiva de osteoclastos primários.

2) A FBP inibe a formação de células multinucleadas $\mathrm{TRAP}^{+}$, sem produzir efeitos citotóxicos.

3) O efeito inibidor da FBP sobre a osteoclastogênese e reabsorção óssea não depende da atividade da PKM2.

4) Em conjunto, os resultados deste trabalho sugerem que a FBP é um metabolito regulador importante do funcionamento dos osteoclastos, demonstrando ser um agente potencial para o tratamento de doenças associadas com alterações na densidade mineral óssea.

5) De modo igual, esses dados ressaltam a importância de processos metabólicos na osteoclastogênese. 


\section{REFERENCIAS}




\section{REFERÊNCIAS}

Adamopoulos IE, Mellins ED. Alternative pathways of osteoclastogenesis in inflammatory arthritis. Nat Rev Rheumatol. 2015 Mar;11(3):189-94. doi: 10.1038/nrrheum.2014.198.

Ahn H, Lee K, Kim JM, Kwon SH, Lee SH, Lee SY, Jeong D. Accelerated Lactate Dehydrogenase Activity Potentiates Osteoclastogenesis via NFATc1 Signaling. PLoS One. 2016 Apr 14;11(4):e0153886. doi: 10.1371/journal.pone.0153886. eCollection 2016.

Alford AI, Kozloff KM, Hankenson KD. Extracellular matrix networks in bone remodeling. Int J Biochem Cell Biol 2015;65:20-31.

Al Mamun MA, Islam K, Alam MJ, Khatun A, et al. Flavonoids isolated from Tridax procumbens (TPF) inhibit osteoclasts differentiation and bone resorption. Biol Res. 2015 Sep 12;48:51. doi: 10.1186/s40659-015-0043-6.

Alva N, Alva R, Carbonell T. Fructose 1,6-Bisphosphate: A Summary of Its Cytoprotective Mechanism. Curr Med Chem. 2016;23(39):4396-4417.

Alves Filho JC, Santos RC, Castaman TA, de Oliveira JR. Anti-inflammatory effects of fructose-1,6bisphosphate on carrageenan-induced pleurisy in rat. Pharmacol Res. 2004 Mar;49(3):245-8.

Alves-Filho JC, Pålsson-McDermott EM. Pyruvate Kinase M2: A Potential Target for Regulating Inflammation. Frontiers in Immunology. 2016;7:145. doi:10.3389/fimmu.2016.00145.

Amano S, Chang YT2, Fukui Y2. ERK5 activation is essential for osteoclast differentiation. PLoS One. 2015 Apr 17;10(4):e0125054. doi: 10.1371/journal.pone.0125054. eCollection 2015.

Anastasiou D, Yu Y, Israelsen WJ, Jiang JK, Boxer MB, Hong BS, Tempel W, Dimov S, Shen M, Jha A, et al. Pyruvate kinase M2 activators promote tetramer formation and suppress tumorigenesis. Nat. Chem. Biol. 2012; 8, 839-847.

Azambuja AA, Lunardelli A, Nunes FB, Gaspareto PB, Donadio MV, Poli de Figueiredo CE, de Oliveira JR. Effect of fructose-1,6-bisphosphate on the nephrotoxicity induced by cisplatin in rats. Inflammation. 2011 Feb;34(1):67-71. doi: 10.1007/s10753-010-9212-5.

Bao L, Qin L, Liu L, Wu Y, et al. Anthraquinone compounds from Morinda officinalis inhibit osteoclastic bone resorption in vitro. Chem Biol Interact. 2011 Nov 15;194(2-3):97-105. doi: 10.1016/j.cbi.2011.08.013. Epub 2011 Sep 10.

Boonen S, Rosenberg E, Claessens F, Vanderschueren D, Papapoulos S. Inhibition of cathepsin K for treatment of osteoporosis. Curr Osteoporos Rep. 2012 Mar;10(1):73-9. doi: 10.1007/s11914-0110085-9. 
Boyce BF, Yamashita T, Yao Z, Zhang Q, Li F, Xing L. Roles for NF-kappaB and c-Fos in osteoclasts. J Bone Miner Metab. 2005;23 Suppl:11-5.

Buckwalter JA, Glimcher MJ, Cooper RR, Recker R. Bone Biology I: structure, blood supply, cells, matrix, and mineralization (Review). Instr Course Lect. 1996;45:371-86.

Cappariello A, Maurizi A, Veeriah V, Teti A. Reprint of: The Great Beauty of the osteoclast. Arch Biochem Biophys. 2014 Nov 1;561:13-21. doi: 10.1016/j.abb.2014.08.009.

Chaneton B, Hillmann P, Zheng L, Martin AC, Maddocks OD, et al. Serine is a natural ligand and allosteric activator of pyruvate kinase M2. Nature. 2012 Nov 15;491(7424):458-62. doi: 10.1038/nature11540. Epub 2012 Oct 14.

Chang X, Wei C. Glycolysis and rheumatoid arthritis. Int J Rheum Dis. 2011 Aug;14(3):217-22. doi: 10.1111/j.1756-185X.2011.01598.x.

Cohen JE, Atluri P, Taylor MD, Grand TJ, Liao GP, Panlilio CM, et al. Fructose 1,6-diphosphate administration attenuates post-ischemic ventricular dysfunction. Heart Lung Circ. 2006 Apr;15(2):119-23. Epub 2006 Feb 15.

Donohoe PH, Fahlman CS, Bickler PE, Vexler ZS, Gregory GA. Neuroprotection and intracellular $\mathrm{Ca}^{2+}$ modulation with fructose-1,6-bisphosphate during in vitro hypoxia-ischemia involves phospholipase C-dependent signaling. Brain Res. 2001 Nov 2;917(2):158-66.

Dombrauckas JD, Santarsiero BD, Mesecar AD. Structural basis for tumor pyruvate kinase M2 allosteric regulation and catalysis. Biochemistry. 2005 Jul 12;44(27):9417-29.

Fahlman CS, Bickler PE, Sullivan B, Gregory GA. Activation of the neuroprotective ERK signaling pathway by fructose-1,6-bisphosphate during hypoxia involves intracellular $\mathrm{Ca} 2+$ and phospholipase C. Brain Res. 2002 Dec 20;958(1):43-51.

Ferron M, Wei J, Yoshizawa T, Del Fattore A, DePinho RA, Teti A, Ducy P, Karsenty G. Insulin signaling in osteoblasts integrates bone remodeling and energy metabolism. Cell. $2010 \mathrm{Jul}$ 23;142(2):296-308. doi: 10.1016/j.cell.2010.06.003.

Fong JE, Le Nihouannen D, Tiedemann K, Sadvakassova G, Barralet JE, Komarova SV. Moderate excess of pyruvate augments osteoclastogenesis. Biol Open. 2013 Mar 22;2(4):387-95. doi: 10.1242/bio.20133269. Print 2013 Apr 15.

Goralski KB, McCarthy TC, Hanniman EA, et al. Chemerin, a novel adipokine that regulates adipogenesis and adipocyte metabolism. J Biol Chem. 2007;282(38):28175-88. 
Guerrini MM, Takayanagi H. The immune system, bone and RANKL. Arch Biochem Biophys. 2014 Nov 1;561:118-23. doi: 10.1016/j.abb.2014.06.003.

Gupta V, Bamezai RN. Human pyruvate kinase M2: a multifunctional protein. Protein Sci. 2010 Nov;19(11):2031-44. doi: 10.1002/pro.505.

Hattersley G, Owens J, Flanagan AM, Chambers TJ. Macrophage colony stimulating factor (M-CSF) is essential for osteoclast formation in vitro. Biochem. Biophys. Res. Commun. 1991, 177:526-531.

He Y, Staser K, Rhodes SD, Liu Y, Wu X, Park SJ, et al. Erk1 positively regulates osteoclast differentiation and bone resorptive activity. PloS one. 2011;6:e24780. doi:10.1371/journal.pone.0024780.

Indo Y, Takeshita S, Ishii KA, Hoshii T, Aburatani H, Hirao A, Ikeda K. Metabolic regulation of osteoclast differentiation and function. J Bone Miner Res. 2013 Nov;28(11):2392-9. doi: 10.1002/jbmr.1976.

Israelsen WJ, Vander Heiden MG. Pyruvate kinase: function, regulation and role in cancer. Semin Cell Dev Biol (2015) 43:43-51. doi:10.1016/j. semcdb.2015.08.004.

Iwamoto K, Miyamoto T, Sawatani Y, Hosogane N, Hamaguchi I, Takami M, et al. Dimer formation of receptor activator of nuclear factor kappaB induces incomplete osteoclast formation. Biochem Biophys Res Commun. 2004 Dec 3;325(1):229-34.

Jurica MS, Mesecar A, Heath PJ, Shi W, Nowak T, Stoddard BL. The allosteric regulation of pyruvate kinase by fructose-1,6-bisphosphate. Structure 1998 Feb;6 (2), 195-210.

Jiang Y, Li X, Yang W, Hawke DH, Zheng Y, Xia Y, et al. PKM2 regulates chromosome segregation and mitosis progression of tumor cells. Mol Cell. 2014 Jan 9;53(1):75-87. doi: 10.1016/j.molcel.2013.11.001.

Kaplan FS. Physical factors in bone remodeling. In:Netter FH. The collection of medical illustrations: musculoskeletal system. New Jersey: Summit, 1991.p.187.

Karaça M, Kiliç E, Yazici B, Demir S, de la Torre JC. Ischemic stroke in elderly patients treated with a free radical scavenger-glycolytic intermediate solution: a preliminary pilot trial. Neurol Res. 2002 Jan;24(1):73-80.

Keller KE, Tan IS, Lee YS. SAICAR stimulates pyruvate kinase isoform M2 and promotes cancer cell survival in glucose-limited conditions. Science. 2012 Nov 23;338(6110):1069-72. doi: 10.1126/science.1224409. Epub 2012 Oct 18. 
Kim HS, Lee NK. Gene expression profiling in osteoclast precursors by insulin using microarray analysis. Mol Cells. 2014 Nov;37(11):827-32. doi: 10.14348/molcells.2014.0223.

Kim JH, Kim N. Regulation of NFATc1 in Osteoclast Differentiation. Journal of Bone Metabolism. 2014;21(4):233-241. doi:10.11005/jbm.2014.21.4.233.

Kim JM, Jeong D, Kang HK, Jung SY, et al. Osteoclast precursors display dynamic metabolic shifts toward accelerated glucose metabolism at an early stage of RANKL-stimulated osteoclast differentiation. Cell Physiol Biochem. 2007, 20(6):935-46.

Kim K, Lee SH, Ha Kim J, Choi Y, Kim N. NFATc1 induces osteoclast fusion via up-regulation of Atp6v0d2 and the dendritic cell-specific transmembrane protein (DC-STAMP). Mol Endocrinol. 2008 Jan;22(1):176-85.

Kong YY, Yoshida H, Sarosi I, Tan HL, Timms E, Capparelli C, et al. OPGL is a key regulator of osteoclastogenesis, lymphocyte development and lymph-node organogenesis. Nature. 1999 Jan 28;397(6717):315-23.

Kumar LD, Karthik R, Gayathri N, Sivasudha T. Advancement in contemporary diagnostic and therapeutic approaches for rheumatoid arthritis. Biomed Pharmacother. 2016 Apr;79:52-61. doi: 10.1016/j.biopha.2016.02.001.

Lee K, Chung YH, Ahn H, Kim H, Rho J, Jeong D. Selective Regulation of MAPK Signaling Mediates RANKL-dependent Osteoclast Differentiation. Int J Biol Sci. 2016 Jan 1;12(2):235-45. doi: 10.7150/ijbs. 13814 .

Lee YS, Kim YS, Lee SY, Kim GH, Kim BJ, Lee SH, et al. AMP kinase acts as a negative regulator of RANKL in the differentiation of osteoclasts. Bone. 2010 Nov;47(5):926-37. doi: 10.1016/j.bone.2010.08.001. Epub 2010 Aug 7.

Li J, Zeng L, Xie J, Yue Z, et al. Inhibition of Osteoclastogenesis and Bone Resorption in vitro and in vivo by a prenylflavonoid xanthohumol from hops. Sci Rep. 2015 Dec 1;5:17605. doi: 10.1038/srep17605.

Lian XY, Xu K, Stringer JL. Oral administration of fructose-1,6-diphosphate has anticonvulsant activity. Neurosci Lett. 2008 Dec 3;446(2-3):75-7. doi: 10.1016/j.neulet.2008.09.042.

Lin LF, Xue XY, Liao MJ, Xiao F, Lv RH, Luo HM. Neurotrophic effects of magnesium fructose 1, 6-diphosphate on cortical neurons. Int J Neurosci. 2012 May;122(5):248-54. doi: 10.3109/00207454.2011.648291. Epub 2012 Jan 20.

Lin J, Lee D, Choi Y, Lee SY. The scaffold protein RACK1 mediates the RANKL-dependent activation of p38 MAPK in osteoclast precursors. Sci Signal. 2015 Jun 2;8(379):ra54. doi: 10.1126/scisignal.2005867. 
Lopes RP, Lunardelli A, Preissler T, Leite CE, Alves-Filho JC, Nunes FB, de Oliveira JR, Bauer ME. The effects of fructose-1,6-bisphosphate and dexamethasone on acute inflammation and T-cell proliferation. Inflamm Res. 2006 Aug;55(8):354-8.

Luo W, Semenza GL. Emerging roles of PKM2 in cell metabolism and cancer progression. Trends Endocrinol Metab (2012) 23(11):560-6. doi:10.1016/j.tem.2012.06.010

Lunt SY, Muralidhar V, Hosios AM, Israelsen WJ, Gui DY, Newhouse L, et al. Pyruvate kinase isoform expression alters nucleotide synthesis to impact cell proliferation. Mol Cell. 2015 Jan 8;57(1):95-107. doi: 10.1016/j.molcel.2014.10.027.

Ma B, Zhang Q, Wu D, Wang YL, Hu YY, Cheng YP, Yang ZD, Zheng YY, Ying HJ. Strontium fructose 1,6-diphosphate prevents bone loss in a rat model of postmenopausal osteoporosis via the OPG/RANKL/RANK pathway. Acta Pharmacol Sin. 2012 Apr;33(4):479-89. doi: 10.1038/aps.2011.177. Epub 2012 Mar 19.

Markov AK, Neely WA, Didlake RH, Terry J 3rd, Causey A, Lehan PH. Metabolic responses to fructose-1,6-diphosphate in healthy subjects. Metabolism. 2000 Jun;49(6):698-703.

Mosmann T. Rapid colorimetric assay for cellular growth and survival: application to proliferation and cytotoxicity assays. J Immunol Methods. 1983 Dec 16;65(1-2):55-63.

Mueller MB, Blunk T, Appel B, Maschke A, Goepferich A, Zellner J, et al. Insulin is essential for in vitro chondrogenesis of mesenchymal progenitor cells and influences chondrogenesis in a dosedependent manner. Int Orthop. 2013 Jan;37(1):153-8. doi: 10.1007/s00264-012-1726-z. Epub 2012 Dec 11.

Nishimoto S, Nishida E. MAPK signalling: ERK5 versus ERK1/2. EMBO Rep. 2006 Aug;7(8):782-6.

Nithianandarajah-Jones GN, Wilm B, Goldring CE, Müller J, Cross MJ. ERK5: structure, regulation and function. Cell Signal. 2012 Nov;24(11):2187-96. doi: 10.1016/j.cellsig.2012.07.007. Epub 2012 Jul 16.

Nunes FB, Graziottin CM, Alves Filho JC, Lunardelli A, Pires MG, Wächter PH, De Oliveira JR. An assessment of fructose-1,6-bisphosphate as an antimicrobial and anti-inflammatory agent in sepsis. Pharmacol Res. 2003 Jan;47(1):35-41.

Oh JH, Lee JY, Joung SH, Oh YT, Kim HS, Lee NK. Insulin enhances RANKL-induced osteoclastogenesis via ERK1/2 activation and induction of NFATc1 and Atp6v0d2. Cell Signal. 2015 Dec;27(12):2325-31. doi: 10.1016/j.cellsig.2015.09.002. Epub 2015 Sep 3.

Palsson-McDermott EM, Curtis AM, Goel G, Lauterbach MA, Sheedy FJ, et al. Pyruvate kinase M2 regulates Hif- $1 \alpha$ activity and IL-1 $\beta$ induction and is a critical determinant of the warburg effect in LPS-activated macrophages. Cell Metab. 2015 Jan 6;21(1):65-80. doi: 10.1016/j.cmet.2014.12.005. 
Park JY, Kim EJ, Kwon KJ, Jung YS, Moon CH, Lee SH, Baik EJ. Neuroprotection by fructose-1,6bisphosphate involves ROS alterations via p38 MAPK/ERK. Brain Res. 2004 Nov 12;1026(2):295301.

Penoni DC, Thomé AT, Melo T, Torres SR. Possíveis ligações entre a osteoporose e a doença periodontal. Rev Bras Reumatol. 2016. http://dx.doi.org/10.1016/j.rbr.2015.12.002

Picerno V, Ferro F, Adinolfi A, Valentini E, Tani C, Alunno A. One year in review: the pathogenesis of rheumatoid arthritis. Clin Exp Rheumatol. 2015 Jul-Aug;33(4):551-8. Epub 2015 Jul 21.

Planas ME, Sánchez S, González P, Rodrigues de Oliveira J, Bartrons R. Protective effect of fructose 1,6-bisphosphate against carrageenan-induced inflammation. Eur J Pharmacol. 1993 Jun 24;237(23):251-5.

Prates TP, Taira TM, Holanda MC, Bignardi LA, Salvador SL, et al. NOD2 contributes to Porphyromonas gingivalis-induced bone resorption. J Dent Res. 2014 Nov;93(11):1155-62. doi: 10.1177/0022034514551770.

PubChem Compd Database. [acesso em 4 abr. 2017]. Disponível em: https://pubchem.ncbi.nlm.nih.gov/compound/10267\#section=Pharmacology-and-Biochemistry

Ramos-Junior ES, Leite GA, Carmo-Silva CC, Taira TM, Neves KB, Colón DF, et al. Adipokine Chemerin Bridges Metabolic Dyslipidemia and Alveolar Bone Loss in Mice. J Bone Miner Res. 2016 Dec 28. doi: 10.1002/jbmr.3072.

Riedel BJ, Gal J, Ellis G, Marangos PJ, Fox AW, Royston D. Myocardial protection using fructose1,6-diphosphate during coronary artery bypass graft surgery: a randomized, placebo-controlled clinical trial. Anesth Analg. 2004 Jan;98(1):20-9.

Santos RC, Moresco RN, Peña Rico MA, Susperregui AR, Rosa JL, Bartrons R, et al. Fructose-1,6bisphosphate reduces the mortality in Candida albicans bloodstream infection and prevents the septicinduced platelet decrease. Inflammation. 2012 Aug;35(4):1256-61. doi: 10.1007/s10753-012-9436-7.

Seok SM, Park TY, Park HS, Baik EJ, Lee SH. Fructose-1,6-bisphosphate suppresses lipopolysaccharide-induced expression of ICAM-1 through modulation of toll-like receptor-4 signaling in brain endothelial cells. Int Immunopharmacol. 2015 May;26(1):203-11. doi: 10.1016/j.intimp.2015.03.029.

Shirai T, Nazarewicz RR, Wallis BB, Yanes RE, Watanabe R, Hilhorst M, et al. The glycolytic enzyme PKM2 bridges metabolic and inflammatory dysfunction in coronary artery disease. J Exp Med. 2016 Mar 7;213(3):337-54. doi: 10.1084/jem.20150900.

Spoden GA, Rostek U, Lechner S, et al. Pyruvate kinase isoenzyme M2 is a glycolytic sensor differentially regulating cell proliferation, cell size and apoptotic cell death dependent on glucose supply. Exp Cell Res. 2009 Oct 1;315(16):2765-74. doi: 10.1016/j.yexcr.2009.06.024. 
Takayanagi H, Kim S, Koga T, et al. Induction and activation of the transcription factor NFATc1 (NFAT2) integrate RANKL signaling in terminal differentiation of osteoclasts. Dev Cell 2002, 3:889901.

Tenenbaum HC, Palangio K. Phosphoethanolamine- and fructose 1,6-diphosphate-induced calcium uptake in bone formed in vitro. Bone Miner. 1987 May;2(3):201-10.

Tompkins KA. The osteoimmunology of alveolar bone loss. Connect Tissue Res. 2016 Mar;57(2):6990. doi: 10.3109/03008207.2016.1140152.

Veras FP, Alves Filho JCF. Estudo dos mecanismos antiinflamatórios da frutose 1,6-difosfato na artrite experimental: papel do receptor de adenosina A2A e das ectonucleotidases CD39 e CD73. BCRP-Fac Medicina Rib Preto. 2014.

Veras FP, Peres RS, Saraiva AL, Pinto LG, Louzada-Junior P, Cunha TM, et al. Fructose 1,6bisphosphate, a high-energy intermediate of glycolysis, attenuates experimental arthritis by activating anti-inflammatory adenosinergic pathway. Scientific Reports. 2015;5:15171. doi:10.1038/srep15171.

Viacava PR. Frutose 1,6 bifosfato, um intermediário da glicólise, regula a produção de IL-10 em macrófagos de forma dependente da via adenosinérgica. Ribeirão Preto: Faculdade de Medicina de Ribeirão Preto, Universidade de São Paulo; 2015.

Williams JP, Blair HC, McDonald JM, et al. Regulation of osteoclastic bone resorption by glucose. Biochem Biophys Res Commun. 1997 Jun 27;235(3):646-51.

Wong N, De Melo J, Tang D. PKM2, a Central Point of Regulation in Cancer Metabolism. Int J Cell Biol. 2013;2013:242513. doi: 10.1155/2013/242513. Epub 2013 Feb 14.

Wong N, Ojo D, Yan J, Tang D. PKM2 contributes to cancer metabolism. Cancer Lett. 2015 Jan 28;356(2 Pt A):184-91. doi: 10.1016/j.canlet.2014.01.031. Epub 2014 Feb 4.

$\mathrm{Xu} \mathrm{K}$, Stringer JL. Pharmacokinetics of fructose-1,6-diphosphate after intraperitoneal and oral administration to adult rats. Pharmacol Res. 2008 Mar;57(3):234-8. doi: 10.1016/j.phrs.2008.01.008. Epub 2008 Feb 2.

Xu X, Zhang Z, Wang W, Yao H, et al. Therapeutic Effect of Cistanoside A on Bone Metabolism of Ovariectomized Mice. Molecules. 2017 Jan 24;22(2). pii: E197. doi: 10.3390/molecules22020197.

Yang J, Zhang X, Wang W, Liu J. Insulin stimulates osteoblast proliferation and differentiation through ERK and PI3K in MG-63 cells. Cell Biochem Funct. 2010 Jun;28(4):334-41. doi: 10.1002/cbf.1668. 
Yang W, Xia Y, Hawke D, Li X, Liang J, Xing D, et al. PKM2 phosphorylates histone H3 and promotes gene transcription and tumorigenesis. Cell. 2012 Aug 17;150(4):685-96. doi: 10.1016/j.cell.2012.07.018.

Yavropoulou MP, Yovos JG. Osteoclastogenesis--current knowledge and future perspectives. J Musculoskelet Neuronal Interact. 2008, 8(3):204-16.

Yu M, Qi X, Moreno JL, Farber DL, Keegan AD. NF- $k B$ signaling participates in both RANKL- and IL-4-induced macrophage fusion: receptor cross-talk leads to alterations in NF-кB pathways. J Immunol. 2011 Aug 15;187(4):1797-806. doi: 10.4049/jimmunol.1002628. Epub 2011 Jul 6. 
ANEXOS 


\section{ANEXOS}

\section{UNIVERSIDADE DE SÃO PAULO}

\section{Faculdade de Ciências Farmacêuticas de Ribeirão Preto}

COMISSÃO DE ÉTICA NO USO DE ANIMAIS

\section{A U T O R I Z A Ç Ã O}

Certificamos que a proposta intitulada "Efeito da O-GlcNacilação sobre a osteclastogênese e reabsorção óssea", registrada sob ํo 15.1.750.60.0, sob a responsabilidade de Sandra Yasuyo Fukada Alves, que envolve a manutenção e utilização de animais pertencentes ao filo Chordata, subfilo Vertebrata (exceto o homem) para fins de pesquisa científica encontra-se de acordo com os preceitos da Lei $n^{\circ} 11.794$, de 8 de outubro de 2008, do Decreto 96.899 , de 15 de julho de 2009, e com as normas editadas pelo Conselho Nacional de Controle da Experimentação Animal (CONCEA), foi aprovada ad referendum em 04/12/2015 pela Comissão de Ética no Uso de Animais da Faculdade de Ciências Farmacêuticas de Ribeirão Preto (CEUA FCFRP).

Lembramos da obrigatoriedade de apresentação do relatório de atividades, em modelo da CEUA, para emissão do certificado, como disposto nas Resoluções Normativas do CONCEA.

\begin{tabular}{|c|c|c|}
\hline Finalidade & $($ ) Ensino ( x ) Pesquisa Científica \\
\hline Vigência da Autorização & 294 & 01/10/2015 a 30/09/2017 \\
\hline Espécie/Linhagem/Raça & Camundongo isogênico C57BL/6 & Camundongo knockout IL-1RKO \\
\hline № de animais & $18 \mathrm{~g} / 6-8$ semanas & $18 \mathrm{~g} / 6$-8 semanas \\
\hline Peso/ldade & Macho & Macho \\
\hline Sexo & Biotério Central da PUSP-RP & Biotério da FMRP \\
\hline Origem &
\end{tabular}

Ribeirão Preto, 05 de junho de 2017.

Ana Patrícia Yatsuda Natsui Coordenadora da CEUA-FCFRP 